\title{
Temporal Profile and Limb-specificity of Phasic Pain-Evoked Changes in Motor Excitability
}

\author{
M. Algoet, a J. Duque, a G. D. Iannetti b,c and A. Mouraux a* \\ a Institute of Neuroscience (IoNS), UniversiteÅL catholique de Louvain, Brussels, Belgium \\ b Department of Neuroscience, Physiology and Pharmacology, University College London, London, United Kingdom \\ c Neuroscience and Behaviour Laboratory, Istituto Italiano di Tecnologia, Rome, Italy
}

Abstract - A fundamental function of nociception is to trigger defensive motor responses to threatening events. Here, we explored the effects of phasic pain on the motor excitability of ipsilateral and contralateral arms. We reasoned that the occurrence of a short-lasting nociceptive stimulus should result in a specific modulation of motor excitability for muscles involved in the withdrawal of the stimulated limb. This was assessed using transcranial magnetic stimulation (TMS) of the left and right primary motor cortex to elicit motor-evoked potentials (MEPs) in three flexor and two extensor muscles of both arms. To assess the time-course of nociception-motor interactions, TMS pulses were triggered 50-2000 ms after delivering short-lasting nociceptive laser stimuli to the left or right hand. We made three main observations. First, nociceptive stimuli induced an early-latency $(100 \mathrm{~ms})$ enhancement of MEPs in flexor muscles of the stimulated hand. Considering its latency, this modulation is likely consequent to nociceptive-motor interactions at spinal level. This early and lateralized enhancement was followed by a later (150-400 ms) MEP reduction in extensor muscles of the stimulated hand and flexor muscles of both hands, predominant at the stimulated hand. Finally, we observed a long-lasting (600-2000 ms) MEP enhancement in muscles of the non-stimulated hand. These later effects of the nociceptive stimulus could reflect nociception-motor interactions occurring at cortical level._2018 IBRO. Published by Elsevier Ltd. All rights reserved.

Key words: nociception, primary motor cortex, transcranial magnetic stimulation, pain, motor-evoked potentials.

*Corresponding author. Address: Institute of Neuroscience (IoNS),

UniversiteÅL catholique de Louvain, avenue Mounier 53 B1.53.04, 1200 Brussels, Belgium. Fax: +32(2)764-53-60.

E-mail address: andre.mouraux@uclouvain.be (A. Mouraux).

Abbreviations: BB, biceps brachialis; CMCT, central motor conduction time; CSP, cutaneous silent period; ECR, extensor carpi radialis; FCR, flexor carpi radialis; FDI, first dorsal interosseous; ISI, inter-stimulus interval; M1, primary motor cortex; MEPs, motor-evoked potentials; NRS, numerical rating scale; NWR, nociceptive withdrawal reflex; rMT, resting motor threshold; $\mathrm{TB}$, triceps brachialis.

\section{INTRODUCTION}

Because of its intrinsic aversive nature, pain strongly influences behavior. For example, following a lesion, pain-related changes in motor behavior can protect from further injury and promote recovery (Hodges and Tucker, 2011; Burns et al., 2016). Most importantly, the ability to generate swift motor responses to the detection of a sudden noxious stimulus is crucial to prevent or limit injury, and is thus essential for survival (Iannetti and Mouraux, 2010).

Nociception-evoked motor responses imply the existence of strong interactions between nociceptive and motor systems (Bank et al., 2013). Such interactions have been clearly demonstrated at spinal level. For example, nociceptive stimulation of the foot elicits a spinal nociceptive withdrawal reflex (NWR) resulting in a

simultaneous activation of flexor muscles and inhibition of extensor muscles of the stimulated limb (Sandrini et al., 2005). Interestingly, this nociceptive response could encompass several reflex modules, each having a characteristic reflex-evoking receptive field, and controlling one or more synergistic muscles (Schouenborg and Kalliomaki, 1990; Andersen et al., 1999). The elicited muscular response would thereby be dependent on the location of the nociceptive stimulus (Andersen, 2007). Similarly, it was shown that high-intensity electrical stimulation of the nociceptive afferents of a digital nerve can transiently interrupt the voluntary muscle contraction of the stimulated limb through spinal inhibitory circuits (Merton, 1951; Caccia et al., 1973; Kranz et al., 1973; 
McLellan, 1973; Uncini et al., 1991; Inghilleri et al., 1997; Floeter, 2003; Kofler, 2003).

There is also evidence supporting the existence of nociception-motor interactions at cortical level, but these interactions have not been characterized as extensively. For example, Frot et al. (2013) found, using depth electrodes implanted in the pre- and post-central gyri of

epileptic patients, that brief nociceptive stimuli delivered to the hand dorsum elicit early-latency responses in the contralateral primary motor cortex (M1), peaking approximately $170 \mathrm{~ms}$ after stimulus onset.

A more direct approach to characterize modulatory effects of nociception on the motor system at cortical level is to assess the effect of nociceptive stimuli on the motor-evoked potentials (MEPs) elicited by transcranial magnetic stimulation (TMS) of M1 (Hallett, 2000; Bestmann and Duque, 2015). Using this approach, Valeriani et al. $(1999,2001)$ found, in studies performed in five healthy volunteers, that noxious heat stimuli delivered to the hand dorsum exert an early (170-270 ms) and transient inhibition of MEPs recorded from the first dorsal interosseous muscle (FDI) (Valeriani et al., 1999) and biceps brachialis (BB) (Valeriani et al., 2001) of the stimulated limb. This inhibition was interpreted as resulting from a change in excitability at cortical level, because MEPs evoked by anodal electrical stimulation of M1, which is thought to directly activate the cortico-spinal tract, were unaffected by the nociceptive stimulus. Here, we aimed to characterize the temporal profile of the modulatory effect of transient nociceptive stimulation of the hand dorsum skin on the excitability of the motor system controlling a number of muscles of the hand and upper limb ipsilateral and contralateral to the stimulated hand. We hypothesized that phasic pain delivered to the hand dorsum facilitates a purposeful defensive reaction in the stimulated limb, which would be reflected in a limb-specific and time-dependent modulation of motor excitability within the flexor muscles involved in the withdrawal of the stimulated limb.

\section{EXPERIMENTAL PROCEDURES}

Participants and experimental design Ten subjects took part in the experiment ( 5 men), aged 20-24 years $(22 \AA\} 1$; mean $\AA$ \} standard deviation). None of the participants had a history of neurological or psychiatric disorder, and all were naive to the purpose of the study. All participants gave written informed consent and received a financial compensation for their participation. The protocol was approved by the institutional ethics committee of the Universite $\AA \mathrm{L}$ catholique de Louvain in accordance to the Declaration of Helsinki.

The experimental design is detailed in Fig. 1. We examined the effect of a nociceptive stimulus delivered to the left or right hand dorsum on the MEPs elicited in flexor (FDI, flexor carpi radialis; FCR) and extensor (extensor carpi radialis; ECR) muscles of the left and right hand.

The time course of the possible modulatory effects of the laser stimulus on motor excitability was characterized by varying the delay between the onset of the laser stimulus and the onset of the TMS pulses delivered over the left and right M1.

We also conducted a supplementary experiment in which we aimed to assess the effects of nociceptive stimulation on two proximal muscles of the upper limb controlling the flexion (BB) and extension (triceps 
brachialis, TB) of the forearm. The design of this experiment was almost the same as that of the main experiment (see below)

Nociceptive stimulation

Participants were seated in a comfortable chair in a dimlylit room with their arms placed on a cushion and their hand palms resting on a table (Fig. 1). A small curtain occluded vision of the hands and laser stimulus. Therefore, participants were not aware of which hand was going to be stimulated. High-intensity nociceptive stimuli were 50 -ms pulses of radiant heat generated by an infrared $\mathrm{CO}_{2}$ laser stimulator (wavelength $10.6 \mathrm{~mm}$; Universite $\AA \mathrm{L}$ catholique de Louvain; Plaghki et al. (1994)). The target of the laser stimulator was visualized by a coaxial HeNe laser beam, and controlled using two mirrors mounted on a computer-controlled 2-axis galvanometer (LSST10.6-12-105-8062-3A, Sintec Optronics, Singapore). The stimuli were delivered to the left or right hand dorsum, in random order. Beam surface area at target site was 80 $\mathrm{mm} 2$. To avoid skin overheating and nociceptor fatigue or sensitization, the target of the laser beam was displaced to a random position on the hand dorsum after each pulse. The minimum distance between two consecutive pulses on the same hand was set to $20 \mathrm{~mm}$. In a preliminary session, laser stimuli of variable energy were delivered to the hand dorsum such as to determine the energy at which the stimuli elicited a clear painful pinprick sensation, detected with reaction times compatible with the conduction velocity of Ad-fibers $(<650 \mathrm{~ms}$; Mouraux et al. (2003)). The same intensity was used on the two hands and kept constant throughout the whole experimental session.

Transcranial magnetic stimulation and MEP

recording

Participants were asked to relax their muscles. Motor responses were obtained simultaneously from the left and right hand, using two figure-of-eight coils (wing internal diameter: $35 \mathrm{~mm}$ ) positioned over the hand representation of the right and left M1. We chose to record MEPs simultaneously from three different muscles to decrease the total number of TMS pulses required to conduct the experiment, a factor known to induce changes in motor cortex excitability (Pellicciari et al., 2016); and the total number of laser stimuli, a factor that can lead to nociceptor habituation or sensitization (Bromm and Treede, 1987a,b; Raij et al., 2003). Moreover, it ensured that the responses from all three muscles were recorded in the same state of vigilance and attentiveness (Derosiere et al., 2015).

Monophasic TMS pulses (approx. $0.1 \mathrm{~ms}$ rise time and $1 \mathrm{~ms}$ total duration) were generated using two Magstim 200 magnetic stimulators (Magstim, Whitland; UK). A 1-ms inter-pulse interval separated the onset of the two pulses, and the order of the two pulses was randomized across trials. The two pulses of TMS were not simultaneous to reduce physical interactions between the electrical fields induced by each of the two coils (Cincotta et al., 2005). A 1-ms inter-pulse interval was chosen as this interval is sufficiently short to avoid M. Algoet et al. / Neuroscience 386 (2018) 240-255 241 inhibitory (Ferbert et al., 1992) or facilitatory (Hanajima et al., 2001) interactions between the two hemispheres. This double-coil TMS approach using a 1-ms inter-pulse interval has been recently validated by Grandjean et al. (2018), in a study showing that MEPs obtained using the double-coil approach to stimulate the left and right M1 are similar to those elicited by single-coil stimulation 
of the left or right M1. It was also shown to be an effective approach to study corticospinal excitability within the context of a motor task (Vassiliadis et al., 2018).

After fitting the participant with an elastic fabric head cap (Electro-cap International, USA), the coils were positioned tangentially to the scalp, with the handle pointing toward the back of the head 45 away from the midline, approximately perpendicular to the central sulcus.

Electromyographic (EMG) signals were recorded using surface electrodes (Ambu, BlueSensor NF-50-

K/12/EU, Ballerup, Denmark) placed over the FDI, FCR and ECR muscles of both hands. The signals were amplified and bandpass filtered on-line $(4-1500 \mathrm{~Hz})$ using a Neurolog signal conditioner (Digitimer; Hertfordshire, UK), and digitized at $5000 \mathrm{~Hz}$ using a CED 1401 (Cambridge Electronics Design; UK).

For each hemisphere, we first identified the optimal coil location to obtain MEPs simultaneously in the contralateral FDI, FCR and ECR muscles. This location was marked on the cap to provide a reference point throughout the experiment. We then determined the minimum intensity required to elicit a measurable MEP in the FCR muscle (peak-to-peak MEP amplitudes $>50$ $\mathrm{mV}$ ) in 5 out of 10 trials. For both left and right FCR muscles, the mean resting motor threshold (rMT) amounted to $43 \AA\} 4 \%$ and $43 \AA$ \} $5 \%$ of maximum stimulator output, respectively. The intensity of TMS used for the experiment was then set to $120 \%$ of this value.

Recording of MEPs following nociceptive stimulation Each trial started by the delivery of a nociceptive laser stimulus to a random position on the left or right hand dorsum. The laser stimulus was always followed by a TMS pulse delivered with a variable interval.

The time intervals between the onset of the laser stimulus and the delivery of the TMS pulses (interstimulus interval; ISI) were 50, 100, 150, 200, 250, 300, $350,400,600,1000$ or $2000 \mathrm{~ms}$ (Fig. 1). The trials were presented in five blocks. Within each block, each trial type was repeated two times, resulting in 44 trials per block (2 11 time intervals 2 laser stimulus locations). The order of the trials was pseudo-randomized across blocks. At the end of each trial (3-4 s after the onset of the laser stimulus), a warning tone prompted the participant to report the intensity of the percept elicited by the laser stimulus using a numerical rating scale (NRS) extending between 0 (no sensation) to 10 (most intense sensation). The inter-trial interval was $6-7 \mathrm{~s}$.

Statistical analyses

Effect of the nociceptive laser stimulus on MEP amplitudes. For each muscle, MEP amplitudes were estimated by measuring the maximum peak-to-peak amplitude of the TMS-evoked EMG response (Fig. 2). MEP amplitudes were expressed as the percentage of change relative to the average amplitude of the MEPs obtained in both limbs at ISI $=50 \mathrm{~ms}$, which served as control (Fig. 3). The rationale for this approach is that $50 \mathrm{~ms}$ after the onset of the rise in skin temperature generated by the laser stimulus, the afferent volley generated by the activation of heat-sensitive nociceptors has not yet reached the spinal cord (because of the time required to reach the thermal activation threshold of these nociceptors, the time required for neural transduction, and the peripheral conduction time) (Bromm and Treede, 1984). Therefore, at ISI $=50 \mathrm{~ms}$, 
the nociceptive afferent volley cannot interact with the descending motor volley generating the MEPs.

If the laser stimulus has no time-dependent effect on motor excitability, the average amplitude of the MEPs elicited 100-2000 ms after the laser stimulus should
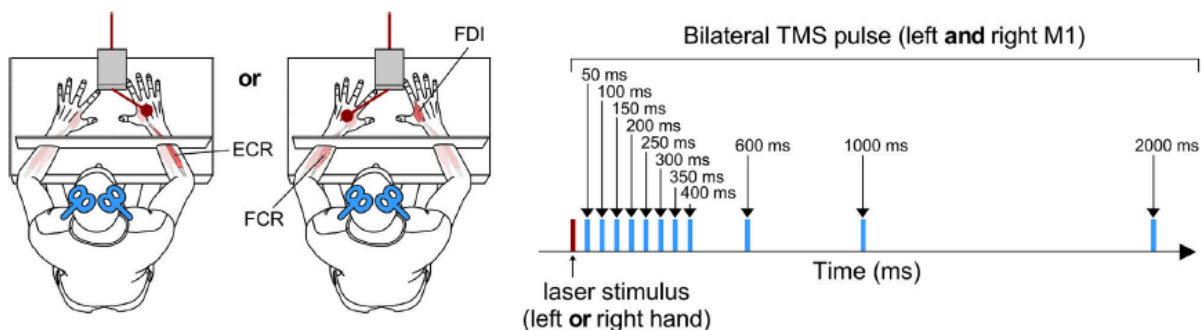

Fig. 1. Experimental design. MEPs were recorded from intrinsic and extrinsic muscles of both hands (flexors: FDI, FCR; extensor: ECR) using quasi-concomitant stimulation of the left and right M1 (TMS inter-pulse interval: $1 \mathrm{~ms}$ ). Intrinsic (FDI) and extrinsic (FCR, hatched in the figure, anatomically more anterior than ECR) muscles of the hand are schematically shown. TMS pulses were systematically preceded by a nociceptive laser stimulus delivered either to the left or to the right hand. The time-interval between the laser stimulus (shown in dark red) and the TMS pulse (shown in light blue) was 50,100, 150, 200, 250, 300, 350, 400, 600, 1000 or $2000 \mathrm{~ms}$. (For interpretation of the references to color in this figure legend, the reader is referred to the web version of this article.)

tend toward the average amplitude of the MEPs elicited at ISI $=50 \mathrm{~ms}$ of the corresponding side. Therefore, for each limb and for each muscle, MEP amplitudes obtained at ISIs 100-2000 ms were compared using paired sample t-tests to the MEP amplitudes obtained at ISI $=50 \mathrm{~ms}$ to assess the time-intervals at which they were either increased or decreased. The results of this first-step analysis were then used to cluster ISIs in four categories prior to comparing changes in motor excitability at the stimulated and non-stimulated limbs. Cluster 1 corresponded to the average MEP amplitude at ISI $=50 \mathrm{~ms}$, serving as control. As detailed in the Results section, cluster 2 corresponded to an earlylatency increase of MEPs observed in FDI and FCR muscles at ISI $=100 \mathrm{~ms}$. Cluster 3 corresponded to a later reduction of MEPs observed in all three muscles at ISIs $=150-400 \mathrm{~ms}$. Finally, cluster 4 corresponded to a late and prolonged MEP facilitation observed in ECR and FDI muscles at ISIs $=600-2000 \mathrm{~ms}$. Using the average amplitude of the MEPs obtained at the ISIs belonging to each cluster, the differential effect of the laser stimulus on motor excitability at the laserstimulated limb and at the contralateral non-laserstimulated limb was assessed separately for each muscle (FDI, FCR, ECR), using a two-way repeatedmeasures ANOVA with the factors 'ISI cluster' (four levels: clusters 1-4) and 'side' of the limb onto which the nociceptive stimulus was applied (two levels: stimulated and non-stimulated limbs). In this analysis, a main effect of 'ISI cluster' on MEP amplitudes would indicate a global non-limb-specific effect of the nociceptive stimulus on motor excitability, whereas the presence of an interaction between the factors 'ISI cluster' and 'side' would indicate a limb-specific effect of the nociceptive stimulus on motor excitability.

The Kolmogorov-Smirnov test was used to assess the assumption of normality. For some measures $(4 / 24)$, the assumption of normality 
was violated according to this test. Importantly, simulation studies have shown that F-tests control well the false-positive rate under conditions of non-normality (Glass et al., 1972; Harwell et al., 1992; Lix et al., 1996), suggesting that $\mathrm{F}$-tests remain robust under conditions of non-normality, especially when group sizes are equal (Donaldson, 1968). A Greenhouse-

Geisser correction for violations of sphericity was used when appropriate. When justified, post hoc comparisons of the responses were performed using paired sample ttests, as follows. For each cluster, MEP amplitudes obtained at the stimulated limb were compared to the

MEP amplitudes obtained at the nonstimulated

limb to assess the timeintervals

at which the laser stimulus

differentially affected excitability in the two limbs. Reported p-values were not corrected for multiple comparisons

(Rothman, 1990; Feise, 2002). Significance

threshold was set at $\mathrm{p}<0.05$.

Relationship with background EMG activity. Variations in EMG background activity could have contributed, at least in part, to differences in MEP amplitudes.

Therefore, the background EMG activity was estimated by computing the root-mean-square (RMS) amplitude from $-100 \mathrm{~ms}$ to the onset of each TMS pulse. For each muscle, the average RMS amplitudes obtained at the different ISIs were compared using a two-way repeatedmeasures ANOVA with the factors 'ISI cluster' (four levels: clusters 1-4) and 'side'.

Relationship with intensity of perception. We also examined whether the effect of the nociceptive stimulus on MEP amplitudes was dependent on the reported intensity of perception. For this purpose, a median split was used to separate the trials of each participant in two categories of equal size (low vs. high intensity of perception). For each muscle, the average MEP amplitudes obtained across the different conditions were then compared using a three-way repeated-measures ANOVA with the factors 'ISI cluster' (four levels: clusters 1-4), 'side' and 'perception' (low vs. high intensity of perception). In this analysis, a main effect of 'perception', or an interaction between the factors 'perception' and the factors 'ISI cluster' or 'side' would indicate that nociceptive stimuli perceived as more or 

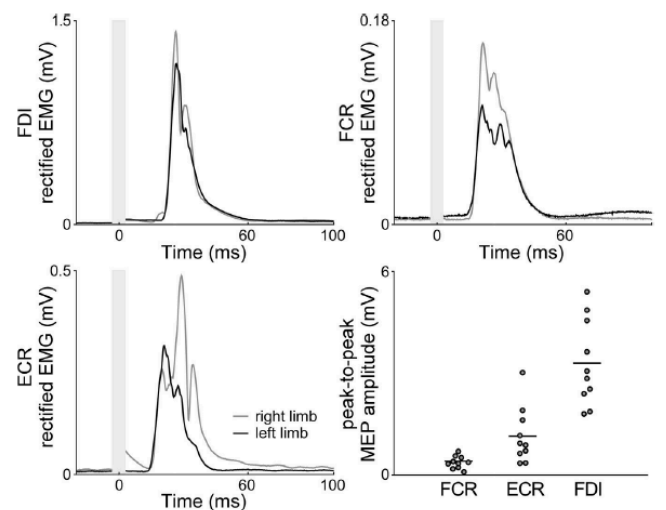

Fig. 2. Group-level average rectified EMG time courses of the MEPs recorded at $\mathrm{ISI}=50 \mathrm{~ms}$ from left and right FDI, FCR and ECR muscles. Subject-and group-level average $\AA$ \} SD peak-topeak amplitude of the MEPs recorded from the different muscles. Note that consistent MEPs were recorded from all muscles, but that their magnitude varied greatly across muscles.

less intense do not exert the same effect on motor excitability.

Baseline MEPs recording. A baseline recording of MEPs was performed at the beginning and at the end of the experiment (20 TMS pulses delivered using a constant $6-7 \mathrm{~s}$ inter-trial interval), to assess potential inter-block cumulative effects of the repeated TMS pulses (Pellicciari et al., 2016) and/or differences related to hand dominance (Triggs et al., 1994). The average amplitude of the MEPs obtained at the two baseline measurements were compared using a two-way repeatedmeasures ANOVA with the factors 'time' (beginning vs. end of the experiment) and 'dominance' (MEPs recorded from the dominant vs. non-dominant limb). Supplemental experiment In order to assess the effect of a nociceptive stimulus delivered to the hand dorsum on more proximal muscles controlling the flexion (BB) and extension (TB) of the forearm, we conducted a supplemental experiment on seven healthy participants ( 4 men), aged $22-24$ years $(23 \AA$ \} 1). Such as in the main experiment, the laser stimuli were delivered to the left or right hand dorsum, in random order. Because it was not possible to position two coils over the more medial M1 representation of proximal upper-limb muscles, only one hemisphere was stimulated, using a single figure-of-eight coil (wing internal diameter: $45 \mathrm{~mm}$ ) over the right or left M1. EMG signals were recorded using surface electrodes placed over the BB and TB muscles of either the dominant hand ( 3 participants) or the non-dominant hand (4 participants). After having identified the optimal coil location to obtain MEPs in both muscles, the minimum intensity required to elicit measurable MEPs in the BB muscles was determined (peak-to-peak MEP amplitudes $>20 \mathrm{mV}$ in 5 out of 10 trials). The mean rMT of the left and right BB muscles amounted to $64 \AA\} 7 \%$ and $68 \AA\}$ $3 \%$ of maximum stimulator output, respectively. The intensity of TMS used for the experiment was then set to $120 \%$ of this value. On the basis of the results of the main experiment, the time intervals between the laser stimulus and the TMS pulse were 50,100,250,300 or $1000 \mathrm{~ms}$. Trials were presented in five blocks. Within each block, each trial combination was repeated four times, resulting in 40 trials per block (4_ 5 time inter vals_2 laser stimulus locations). Maximum peak-topeak MEP amplitudes were measured and expressed 
as the percentage of change relative to the average amplitude of the MEPs obtained at both limbs at ISI $=5$

$0 \mathrm{~ms}$. For each muscle, the average amplitude of the

MEPs was compared using a two-way repeatedmeasures

ANOVA with the factors 'ISI' $(50,100,250$,

300 , and $1000 \mathrm{~ms}$ ) and 'side' of the limb onto which the nociceptive stimulus was applied (stimulated vs. nonstimulated hand).

\section{RESULTS}

Nociception-motor interactions in flexor and extensor muscles of the hand

Effect of the nociceptive laser stimulus on MEP amplitudes. Consistent MEPs were recorded from all three muscles controlling flexion and extension of the hands (Fig. 2). The nociceptive stimulus appeared to induce a consistent sequence of changes in MEP

\section{FDI}

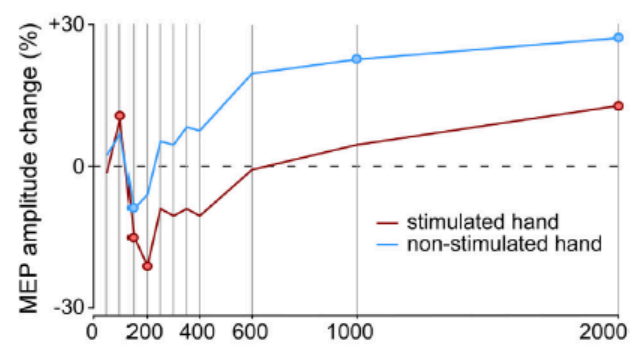

FCR

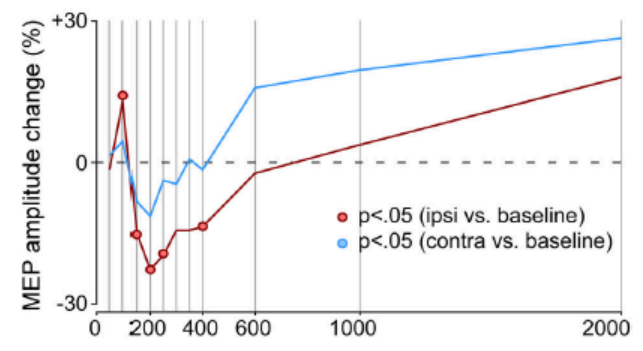

ECR

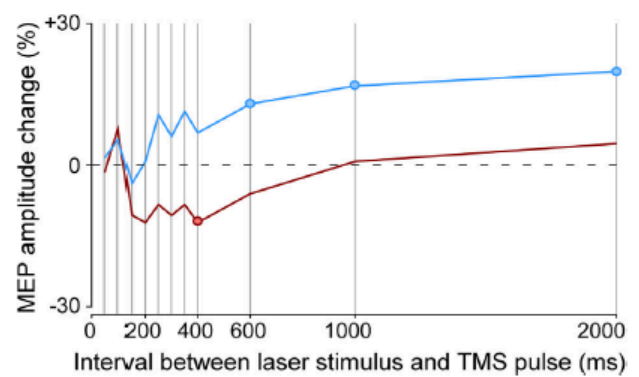

Fig. 3. Effect of the nociceptive laser stimulus delivered to the hand dorsum on the magnitude of the MEPs elicited in flexor (FDI, FCR) and extensor (ECR) muscles of the laser-stimulated hand (dark red) and non-laser-stimulated hands (light blue). X-axis: time-interval between the onset of the nociceptive laser stimulus and the onset of the TMS pulse. Y-axis: MEP amplitude, expressed as the percentage of change relative to the MEPs obtained at ISI $=50 \mathrm{~ms}$. The red and blue dots show the time points at which the change in MEP amplitudes was significantly different from MEPs recorded at ISI $=50 \mathrm{~ms}$. (For interpretation of the references to color in this figure legend, the reader is referred to the web version of this article.)

amplitude in all three muscles (Fig. 3). The paired-sample comparison of the MEP amplitudes obtained at ISI $=50$ ms with the MEP amplitudes at ISIs 100-2000 ms in each 
muscle led us to group the different ISIs in four separate clusters (Table 1). Cluster 1 consisted in the MEPs obtained at ISI $=50 \mathrm{~ms}$, serving as control. Cluster 2 consisted in the MEPs obtained at ISI $=100 \mathrm{~ms}$. At this early-latency ISI, an increase in amplitude was observed in the FDI and FCR muscles. Cluster 3 consisted in the MEPs obtained at ISIs $150-400 \mathrm{~ms}$. At these ISIs, a reduction of amplitude was observed in all three muscles. Finally, cluster 4 consisted in the MEPs obtained at ISIs 600-2000 ms. At these ISIs, a late and prolonged increase was observed in ECR and FDI muscles of the non-laser-stimulated hand.

For each of the three muscles, the repeatedmeasures ANOVA showed a significant interaction between the factors 'ISI cluster' and 'side' (laserstimulated limb vs. non-laser-stimulated limb), indicating that the nociceptive stimulus had a differential effect on the magnitude of the MEPs recorded from muscles of the laser-stimulated limb as compared to the non-laserstimulated limb (Table 2)

For cluster 2 (ISI $=100 \mathrm{~ms}$ ), post hoc comparisons of the MEPs obtained at the laser-stimulated and non-laserstimulated limbs showed that the early-latency enhancement of MEPs was significantly greater in the FCR muscle of the laser-stimulated hand as compared to the non-laser-stimulated hand (Table 3 and Fig. 4). For cluster 3 (ISIs $150-400 \mathrm{~ms}$ ), the mid-latency reduction of MEPs was significantly stronger in all three muscles of the laser-stimulated limb as compared to the non-laser stimulated limb. Finally, for cluster 4 (ISIs 600-2000 ms), the amplitudes of the MEPs obtained from the FDI and ECR muscles of the non-laserstimulated limb were significantly greater as compared to the same muscles of the laser-stimulated limb. Background EMG activity. In all muscles, the two-way repeated-measures ANOVA conducted on the measures of background EMG activity showed no main effect of 'side' (FDI: $\mathrm{F}(1,9)=0.33, \mathrm{p}=0.578, \mathrm{~g}_{2}=0.036$; FCR: $\mathrm{F}_{(1,9)}=0.36, \mathrm{p}=0.566, \mathrm{~g}_{2}=0.038$; ECR: $\mathrm{F}_{(1,9)}=$ $0.14, \mathrm{p}=0.718, \mathrm{~g}_{2}=0.015$ ), no main effect of 'IS cluster' (FDI: $\mathrm{F}_{(3,27)}=2.38, \mathrm{p}=0.092, \mathrm{~g}_{2}=0.209$; FCR: $\mathrm{F}(1.4,12.1)=3.81, \mathrm{p}=0.065, \mathrm{~g}_{2}=0.297$; $\mathrm{ECR}$ : $\left.\mathrm{F}(1.4,12.5)=0.51, \mathrm{p}=0.546, \mathrm{~g}_{2}=0.054\right)$, and no interaction between the two factors (FDI: $\mathrm{F}_{(3,27)}=0.28$, $\mathrm{p}=0.841, \mathrm{~g}_{2}=0.03$; FCR: $\mathrm{F}(1.3,12)=1.87, \mathrm{p}=0.199$, $\mathrm{g}_{2}=0.172$; ECR: $\left.\mathrm{F}_{(3,27)}=0.28, \mathrm{p}=0.841, \mathrm{~g}_{2}=0.03\right)$. Intensity of pain perception. The three-way repeatedmeasures ANOVA assessing whether the effect of the nociceptive stimulus on motor excitability was dependent on the intensity of the elicited percept showed no significant main effect of 'perception' (FDI: $\mathrm{F}_{(1,9)}=2.98, \mathrm{p}=0.118, \mathrm{~g}_{2}=0.249 ; \mathrm{FCR}: \mathrm{F}_{(1,9)}=$ $0.71, \mathrm{p}=0.422, \mathrm{~g}_{2}=0.073$; ECR: $\mathrm{F}(1,9)=4.56, \mathrm{p}=$ $0.062, \mathrm{~g}_{2}=0.336$ ) and no significant 'perception' $\mathrm{x}$ 'side' interaction (FDI: $\mathrm{F}_{(1,9)}=1.59, \mathrm{p}=0.239$, $\mathrm{g}_{2}=$ 0.15 ; FCR: $\mathrm{F}(1,9)=0.56, \mathrm{p}=0.474, \mathrm{~g}_{2}=0.058$; ECR: $\mathrm{F}_{(1,9)}=0.81, \mathrm{p}=0.391, \mathrm{~g}_{2}=0.083$ ) or 'perception' $\mathrm{x}$ 'ISI cluster' interaction (FDI: $\mathrm{F}(1.9,17.2)=0.81, \mathrm{p}=$ $0.458, \mathrm{~g}_{2}=0.082$; FCR: $\mathrm{F}_{(3,27)}=0.41, \mathrm{p}=0.745$, $\mathrm{g}_{2}$ $=0.044$; ECR: $\mathrm{F}(1.5,13.8)=1.29, \mathrm{p}=0.297, \mathrm{~g}_{2}=$

$0.125)$. There was also no three-way interaction (FDI: $\mathrm{F}(3,27)=0.18, \mathrm{p}=0.908, \mathrm{~g}_{2}=0.02 ; \mathrm{FCR}: \mathrm{F}_{(3,27)}=1.8$, $\mathrm{p}=0.172, \mathrm{~g}_{2}=0.166 ; \mathrm{ECR}: \mathrm{F}_{(3,27)}=1.78, \mathrm{p}=0.174$, $\left.\mathrm{g}_{2}=0.165\right)$.

Baseline MEPs. Consistent MEPs were recorded from the FDI, FCR and ECR muscles of both hands, both before the TMS-laser session (FDI: $3.4 \AA\} 2.0 \mathrm{mV}$, FCR: 
$0.3 \AA\} 0.2 \mathrm{mV}$, ECR: $0.8 \AA\} 0.4 \mathrm{mV})$ and after the TMSlaser session (FDI: $2.9 \AA\} 2.2 \mathrm{mV}$, FCR: $0.3 \AA\} 0.2 \mathrm{mV}$,

ECR: $0.9 \AA$ \} $1.0 \mathrm{mV}$ ). In all three muscles, the two-way

repeated-measures ANOVA showed no significant main

effects of 'time' (FDI: $\mathrm{F}(1,9)=1.82, \mathrm{p}=0.21, \mathrm{~g}_{2}=$

0.168; FCR: $\mathrm{F}(1,9)=0.61, \mathrm{p}=0.457, \mathrm{~g}_{2}=0.063$; ECR:

$\left.\mathrm{F}(1,9)=0.37, \mathrm{p}=0.558, \mathrm{~g}_{2}=0.04\right)$, and 'dominance'

(FDI: $F_{(1,9)}=0.96, p=0.354, g_{2}=0.096$; FCR: $F_{(1,9)}$

$=0.57, \mathrm{p}=0.470, \mathrm{~g}_{2}=0.06$; ECR: $\mathrm{F}(1,9)=1.63, \mathrm{p}=$

$0.234, \mathrm{~g}_{2}=0.153$ ), as well as no interaction between

the two factors (FDI: $\mathrm{F}_{(1,9)}=1.40, \mathrm{p}=0.266$, $\mathrm{g}_{2}=$

0.135 ; FCR: $\mathrm{F}_{(1,9)}=1.29, \mathrm{p}=0.286, \mathrm{~g}_{2}=0.125$; ECR:

$\left.\mathrm{F}_{(1,9)}=0.02, \mathrm{p}=0.88, \mathrm{~g}_{2}=0.003\right)$.

Nociception-motor interactions in flexor and extensor

muscles of the forearm (supplemental experiment). Consistent

MEPs were recorded from the $\mathrm{BB}$ and TB muscles

of the two forearms. However, interpretation of potential

nociception-motor interactions in these muscles was

Table 1. Nociception-motor interactions in flexor and extensor muscles of the hand. Time course of the effects of the nociceptive stimulus on the MEPs elicited in the FDI, FCR and ECR muscles of the laser-stimulated and non-laser-stimulated hands. For each limb, MEP amplitudes obtained at ISIs 100-2000 ms were compared to the MEP amplitudes obtained at ISI $=50 \mathrm{~ms}$ using paired-sample t-tests. Significant increases and decreases in MEP amplitudes are shown in dark red and light blue, respectively. The degrees of freedom are equal to nine for all paired-sample t-tests. $" p<0.05$; ${ }^{* *} p<0.005$

\begin{tabular}{lllllllllll}
\hline ISI (ms) & 100 & 150 & 200 & 250 & 300 & 350 & 400 & 600 & 1000 & 2000 \\
\hline \multicolumn{2}{l}{ Laser-stimulated hand } \\
\hline FDI & $.006^{*}$ & $.004^{* *}$ & $.002^{* *}$ & .198 & .159 & .258 & .054 & .884 & .135 & $.042^{*}$ \\
FCR & $.023^{*}$ & $.028^{*}$ & $.007^{*}$ & $.026^{*}$ & .056 & .093 & $.013^{*}$ & .921 & .1 & .128 \\
ECR & .05 & .083 & .052 & .151 & .072 & .212 & $.019^{*}$ & .339 & .453 & .06 \\
Non-laser-stimulated hand & & & & & & & & \\
\hline FDI & .354 & $.037^{*}$ & .169 & .675 & .777 & .399 & .319 & .068 & $.012^{*}$ & $.023^{*}$ \\
FCR & .596 & .128 & .077 & .304 & .182 & .889 & .663 & .271 & .056 & .128 \\
ECR & .344 & .196 & .86 & .313 & .498 & .107 & .173 & $.017^{*}$ & $.004^{* *}$ & $<.001^{* *}$ \\
\hline
\end{tabular}

limited by the fact that the magnitude of MEPs recorded in these muscles was markedly lower than the magnitude of MEPs obtained from hand muscles in the main experiment (Fig. 5). Subject-and group-level averages of the change in MEP amplitude relative to baseline are shown in Fig. 5. The repeated-measures ANOVA with the factors 'ISI' (50, 100, 250, 300, and $1000 \mathrm{~ms})$ and 'side' (stimulated vs. non-stimulated hand) showed no significant main effects of 'ISI' (BB: $F_{(4,24)}=1.27, p=$ $0.311, \mathrm{~g}_{2}=0.174$; TB: $\mathrm{F}(12,11.7)=0.71, \mathrm{p}=0.509$, $\mathrm{g}_{2}$ $=0.106$ ), 'side' (BB: $F(1,6)=0.63, \mathrm{p}=0.457, \mathrm{~g}_{2}=$ 0.095; TB: $\left.F(1,6)=5.14, \mathrm{p}=0.064, \mathrm{~g}_{2}=0.462\right)$ and no significant two-way 'side' $\mathrm{x}$ 'ISI' interaction (BB: $\mathrm{F}(4,24)$ $=1.89, \mathrm{p}=0.145, \mathrm{~g}_{2}=0.24$; TB: $\mathrm{F}_{(4,24)}=1.59, \mathrm{p}=$ $0.21, \mathrm{~g}_{2}=0.209$ ). No significant modulatory effect of the nociceptive stimulus was thus observed in either muscles (Fig. 6). In all muscles, there was also no significant change of the background EMG activity. The two-way repeated-measures ANOVA showed no main effect of 'side' (BB: $F(1,6)=0.01, p=0.91, g_{2}=0.002$; TB: $\left.\mathrm{F}_{(1,6)}=2.68, \mathrm{p}=0.153, \mathrm{~g}_{2}=0.309\right)$, no main effect of 'ISI' (BB: $\mathrm{F}(1.92,11.49)=0.91, \mathrm{p}=0.425$, $\mathrm{g}_{2}=$ 0.132; TB: $\left.\mathrm{F}(4,24)=2.21, \mathrm{p}=0.099, \mathrm{~g}_{2}=0.269\right)$, and no interaction between the two factors $(\mathrm{BB}: \mathrm{F}(1.4,8.37)=$ $1.43, \mathrm{p}=0.279, \mathrm{~g}_{2}=0.193$; TB: $\mathrm{F}(1.25,7.5)=1.17, \mathrm{p}=$ $0.33, \mathrm{~g}_{2}=0.163$ ). 


\section{DISCUSSION}

In this study, we characterized the temporal profile of the effects of a transient nociceptive stimulus delivered to the hand dorsum on the motor excitability of extensor and flexor muscles of the stimulated and non-stimulated arm. We hypothesized that the occurrence of phasic pain delivered to one hand would modulate motor excitability in a limb-specific (stimulated vs. nonstimulated limb) and possibly muscle-specific (flexor muscles involved in the withdrawal of the stimulated limb vs. other muscles) manner, with a time-specific profile.

Our results can be summarized as follows. First, 100 $\mathrm{ms}$ after the onset of the nociceptive stimulus, the responses in flexor muscles of the stimulated hand (FDI and FCR) were significantly increased. This enhancement was observed at both hands, but was significantly more pronounced at the hand which received the nociceptive stimulus, at least for the FCR muscle. A trend toward an MEP enhancement at ISI= $100 \mathrm{~ms}$ was also observed in the extensor muscle of the stimulated hand (ECR). Previous studies have suggested that, at ISI $=100 \mathrm{~ms}$, the nociceptive afferent volley has not yet reached its cortical projection sites (Xu et al., 1995; Spiegel et al., 1996; Valentini et al., 2012a,b). Therefore, it is likely that the enhancement observed at ISI $=100-\mathrm{ms}$ results from nociceptive-motor interactions occurring at spinal level. Second, this initial enhancement was followed by a reduction of MEP amplitudes extending between 150 and 400 $\mathrm{ms}$ after the presentation of the nociceptive stimulus. This reduction was significantly more pronounced at the stimulated hand, and observed in both flexor and extensor hand muscles. Third, between 600 and $1000 \mathrm{~ms}$ we observed a sustained enhancement of the MEPs obtained from the non-laser-stimulated limb as compared to the laser-stimulated limb. Importantly, these changes in MEP amplitude were not the consequence of changes in background EMG activity, which remained similar at all ISI clusters, and at both limbs.

Early-latency increase of motor excitability at the stimulated hand

At an ISI of $50 \mathrm{~ms}$ between the onset of the laser stimulus and the onset of the TMS pulse, the nociceptive afferent volley does not have enough time to reach spinal projection sites and exert an effect on the motor volley generated by the TMS pulse. Indeed, considering the time required for the laser stimulus to bring skin temperature above the thermal activation threshold of heat-sensitive nociceptors and the time required for the transduction of the stimulus into a neural impulse (Bromm and Treede, 1984), the delay between the onset of the laser stimulus and receptor activation should be at least $40 \mathrm{~ms}$. To this delay, one must then add the peripheral conduction time of the nociceptive afferent volley (Kakigi et al., 1991; Tran et al., 2001). Bromm and Treede (1987a,b) estimated the mean conduction velocity of Ad fibers activated by brief pulses of radiant heat to be 
Table 2. Two-way repeated-measures ANOVA comparing, for each flexor/extensor muscle of the hand (FDI, FCR, ECR), the MEPs elicited by TMS pulses delivered $50 \mathrm{~ms}$ (ISI cluster 1), $100 \mathrm{~ms}$ (ISI cluster 2), 150-400 ms (ISI cluster 3) and 600-2000 ms (ISI cluster 4) after the onset of the nociceptive stimulus (factor 'ISI cluster'), and recorded from muscles of the laser-stimulated and non-laser-stimulated hands (factor 'side'). ${ }^{*} p<0.05$; ** $p<0.005$

\begin{tabular}{llllllllll}
\hline Factors & FDI & & \multicolumn{3}{l}{ FCR } & \multicolumn{3}{l}{ ECR } \\
\hline ISI cluster & $F_{3,27}=6.84$ & $p=.001^{* *}$ & $\eta^{2}=.432$ & $F_{1.5,13.5}=7.61$ & $p=.009^{*}$ & $\eta^{2}=.458$ & $F_{3,27}=5.81$ & $p=.003^{* *}$ & $\eta^{2}=.392$ \\
Side & $F_{1,9}=10.92$ & $p=.009^{*}$ & $\eta^{2}=.548$ & $F_{1,9}=7.7$ & $p=.022^{*}$ & $\eta^{2}=.461$ & $F_{1,9}=26.32$ & $p=.001^{* *}$ & $\eta^{2}=.745$ \\
ISI $\times$ side & $F_{3,27}=9.5$ & $P<.001^{* *}$ & $\eta^{2}=.513$ & $F_{1.27,11.4}=5.1$ & $p=.039^{*}$ & $\eta^{2}=.36$ & $F_{1.4,12.8}=9.9$ & $p=.005^{*}$ & $\eta^{2}=.523$ \\
\hline
\end{tabular}

Table 3. Post-hoc comparisons (paired-sample t-tests) of the MEPs elicited in the FDI, FCR and ECR muscles of the laser-stimulated and non-laser-stimulated hands, at ISI $=100 \mathrm{~ms}$ (cluster 2), ISI = 150$400 \mathrm{~ms}$ (cluster 3 ) and ISI $=600-2000 \mathrm{~ms}$ (cluster 4). The degrees of freedom are equal to nine for all paired-sample $t$-tests. ${ }^{*} p<0.05$; of freedom

\begin{tabular}{llll}
\hline & FDI & FCR & ECR \\
\hline Cluster 2 & .369 & $.049^{\star}$ & .629 \\
ISI $=100 \mathrm{~ms}$ & & & \\
Cluster 3 & $<.001^{\star \star}$ & $.001^{\star \star}$ & $<.001^{\star \star}$ \\
ISI $=150-400 \mathrm{~ms}$ & & .081 & $<.001^{\star \star}$ \\
Cluster 4 & $.012^{\star}$ & .081 & \\
ISI $=600-2000 \mathrm{~ms}$ & & & \\
\hline
\end{tabular}

approximatively $14 \mathrm{~m} / \mathrm{s}$. The peripheral conduction distance separating the hand dorsum from the cervical spinal cord is in the range of $90 \mathrm{~cm}$. Thus, approximately $60 \mathrm{~ms}$ is required for the nociceptive afferent volley to reach the spinal cord. Therefore, considering (1) the time required for receptor activation and (2) the peripheral conduction distance, the afferent volley elicited by the laser pulse can be expected to reach the spinal cord approximately $100 \mathrm{~ms}$ after stimulation onset (Tarkka et al., 1992). This latency must then be compared to the central motor conduction time (CMCT), i.e. the time required for the descending motor volley generated by the TMS pulse to reach spinal motoneurons. In healthy subjects, normal values of CMCT are in the range of 4-8 ms (Rossini et al., 1987; Claus et al., 1988; Homberg et al., 1991). Similarly, descending indirect volleys (I-waves) have been recorded in humans with cervical epidural electrodes with latencies of up to $\AA\} 10 \mathrm{~ms}$ after delivering TMS over M1 (Di Lazzaro et al., 1998, 2004). Moreover, excitatory postsynaptic potentials generated in spinal motoneurons can

last as long as 10-20 ms (Curtis and Eccles, 1959; Landgren et al., 1962; Rall et al., 1967). Taking this into account, when the time-interval between the onset of the laser stimulus and the onset of the TMS pulse was $50 \mathrm{~ms}$, the descending motor volley has already been fully transmitted to peripheral efferents at the time the nociceptive input reaches the spinal cord.

In contrast, when the laser stimulus was delivered $100 \mathrm{~ms}$ before the TMS pulse, the nociceptive input conveyed by myelinated Ad fibers has enough time to interact with the descending motor volley at spinal level, but it does not have enough time to interact at cortical level. Indeed, studies have shown that the first cortical response to laser stimuli delivered to the hand dorsum occurs approximately 140-180 ms after onset (Xu et al., 1995; Spiegel et al., 1996; Valentini et al., 2012a,b;

Lenoir et al., 2017). Moreover, depth recordings performed in epileptic patients have shown that laser stimuli delivered to the hand dorsum can elicit responses in M1 starting approximately $120 \mathrm{~ms}$ after stimulation onset, and peaking $170 \mathrm{~ms}$ after stimulation onset (Frot et al., 2013). For these reasons, the early-latency enhancement of motor excitability observed at ISI $=100 \mathrm{~ms}$ was most probably related to a segmental effect of Ad fiber nociceptive 
input on the excitability of spinal motoneurons.

Although less investigated than in the lower limb, upper

limb nociceptive reflex activities can be recorded following

noxious electrical stimulation of the ulnar nerve as well as

the fingers (Cambier et al., 1974; Bromm and Treede,

1980; Campbell et al., 1991; Bouhassira et al., 1993;

Floeter et al., 1998; Serrao et al., 2006, 2012; Eckert

and Riley, 2013). Such as for the lower limbs, this reflex

activity could constitute a protective withdrawal response

(Serrao et al., 2006; Peterson et al., 2014). Whether a

parallel can be drawn between our observation and the

NWR remains an open question. The early latency of

our effect $(100 \mathrm{~ms})$ is compatible with the fact that the

NWR can be observed $60-120 \mathrm{~ms}$ after noxious electrical

stimulation of the ulnar nerve (Cambier et al., 1974). The
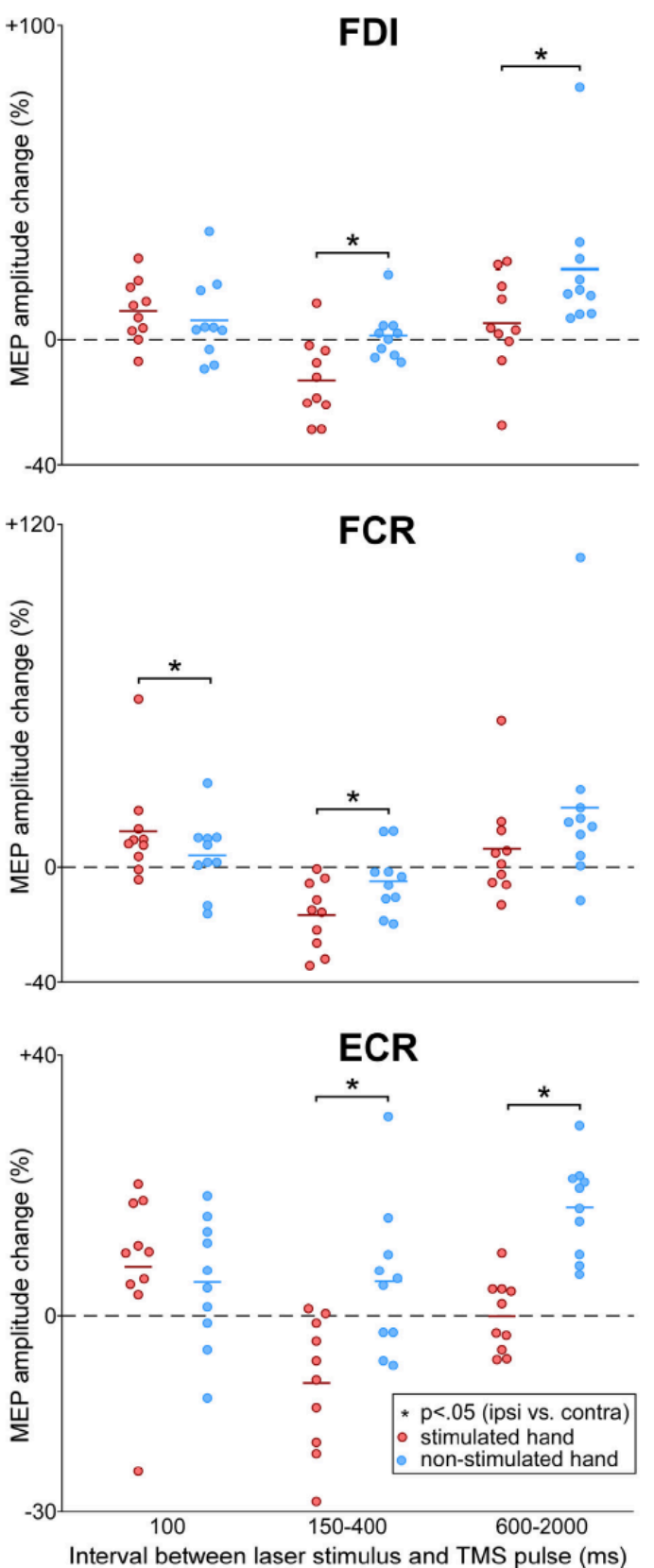
Fig. 4. Subject-and group-level average $\AA$ \} SD of the MEPs expressed as the percentage of change in MEP amplitude in the FDI, FCR and ECR muscles of the laser-stimulated and non-laserstimulated limb at ISI $=100 \mathrm{~ms}$ (cluster 2), ISI $=150-400 \mathrm{~ms}$ (cluster 3 ) and ISI $=600$ $2000 \mathrm{~ms}$ (cluster 4), relative to the MEPs obtained at ISI=50 ms (cluster 1). The asterisks indicate the

clusters at which the magnitude of the MEPs obtained at the laserstimulated

and non-laser-stimulated limbs were significantly different from one another (paired-sample t-tests).

relatively early onset of this reflex activity can be explained by the overlap of RII and RIII components, respectively conveyed by non-nociceptive and nociceptive inputs (Floeter et al., 1998). Notably, our results suggest that the laser stimulus affects similarly the MEP amplitudes recorded from flexor and extensor hand muscles (Figs. 3 and 4), whereas it could have been expected that noxious stimulation would induce a differential modulation of motor excitability in muscles involved vs. not involved in limb withdrawal, i.e. flexor vs. extensor muscles. Supporting our results, several studies have observed simultaneous reflex activity in flexor and extensor muscles, both at the upper and lower limbs (Grimby, 1963; Floeter et al., 1998; Peterson et al., 2014), the activation pattern depending on the location of the nociceptive stimulus and the position of the limbs (Andersen et al., 1999; Andersen, 2007). Considering the biomechanical function of the muscles investigated in the present study, it can be argued that the limb posture (hand palms resting on a table) and the location of the nociceptive stimulus (hand dorsum) would prevent us from observing a withdrawal response in intrinsic (FDI) and extrinsic (FCR) flexor muscles of the hand. Nevertheless, a NWR in the FCR muscle has been described at rest in a semi-flexed position similar to that used in our study (Serrao et al., 2006) and has been recorded from the FDI muscle after delivering noxious electrical stimuli to different fingers (index, middle and fifth finger) (Floeter et al., 1998). Also, the "cutaneous silent period" (CSP), which is thought to be an inhibitory component of a defensive reflex (Inghilleri et al., 1997), can be evoked in the FDI muscle after noxious electrical stimulation of both the index (Floeter et al., 1998) and the hand dorsum (Romaniello et al., 2004; Kahya et al., 2010). Moreover, while the influence of limb position is well established for the lower limb (Andersen, 2007), few studies have investigated this for the upper-limb withdrawal reflex and have found inconsistent results (Eckert and Riley, 2013; Peterson et al., 2014).

Mid-latency decrease of motor excitability at the stimulated hand

Following the transient early-latency enhancement of the responses recorded in flexor hand muscles, there was a longer-lasting decrease of MEP amplitudes extending between 150 and $400 \mathrm{~ms}$ after the onset of the nociceptive stimulus. This decrease was significantly more pronounced at the hand which received the nociceptive stimulus. It was present in flexor and extensor hand muscles. This observation is in agreement with reports of a decreased motor excitability in hand muscles after noxious electrical stimulation (Inghilleri et al., 1995; Kofler et al., 1998, 2001, 2008; Tamburin et al., 2001; Urban et al., 2004) or during phasic painful heat stimulation (Dube and Mercier, 2011). 

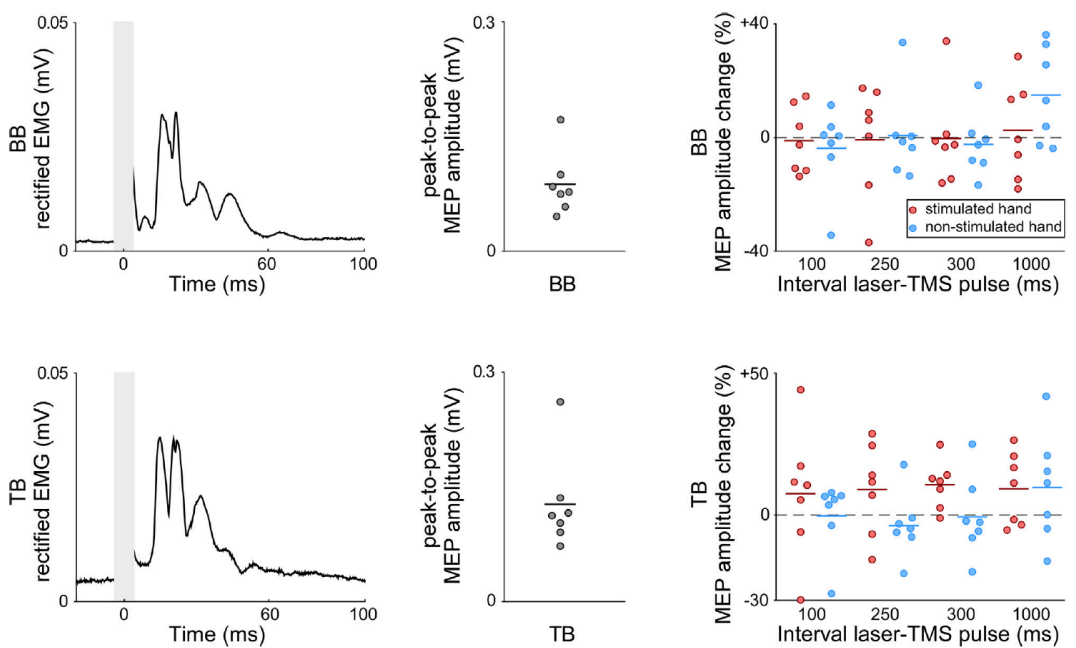

Fig. 5. Left panel. Group-level average rectified EMG time courses of the MEPs recorded at ISI= $50 \mathrm{~ms}$ from forearm flexor (BB) and extensor (TB) muscles in the supplemental experiment. Middle panel. Subject-and group-level average $\AA$ \} SD peak-to-peak amplitude of the MEPs recorded from the different muscles. Note that consistent MEPs were recorded from all muscles, but that their magnitudes were, on average, of much smaller magnitude than the MEPs recorded from distal muscles in the main experiment. Right panel. Subjectand group-level average $\AA$ \}SD of the MEPs obtained at ISI=100-1000 ms, expressed as the percentage of change relative to the MEPs obtained at ISI $=50 \mathrm{~ms}$. The $\mathrm{x}$-axis represents the time-interval between the onset of the laser stimulus and the onset of the TMS pulse.

Similarly, Valeriani et al. (1999) found a significant reduction of MEP amplitudes in the FDI muscle 170-270 ms after the delivery of a thermal nociceptive stimulus on the stimulated hand dorsum.

At these latencies, the nociceptive input conveyed by Ad fibers has enough time to reach M1 before the onset of the TMS pulse (Frot et al., 2013). Therefore, this effect could be related to nociception-motor interactions occurring at cortical level (exerting an effect on the excitability of M1) and/or spinal level. Several studies have shown that nociceptive laser stimuli can induce a significant reduction of the sensorimotor mu rhythm, maximal over the hemisphere contralateral to the stimulated hand (Raij et al., 2004; Ploner et al., 2006). Considering that these stimulus-evoked changes in mu rhythm magnitude have been shown to index context-dependent changes in the level of activation of sensorimotor cortices (Valentini et al., 2012a,b), and considering the latency of the effect of nociceptive stimulation on mu rhythm magnitude (180-570 ms; Raij et al., 2004), the decrease of MEP amplitudes we observed at $150-400 \mathrm{~ms}$ could be related to stimulus-evoked changes in cortical sensorimotor oscillatory activity. Mechanisms underlying theses changes in cortical activity are still poorly understood. Nociceptive inputs could act through spinothalamic projections to brain region involved in motor function such as M1 (Frot et al., 2013) or cingulate areas (Dum et al., 2009) involved in motor control of the upper limb (Turken and Swick, 1999) including defensive movements (Cooke and Graziano, 2003, 2004; Moayedi et al., 2015). Furthermore, interactions between brain regions underlying the processing of nociceptive inputs and those supporting motor control could also be involved (Suppa et al., 2013). In agreement, hemodynamic changes following acute pain have been observed in several motor structures including the cerebellum, the supplementary motor area, and the lenticular and caudate nuclei (Peyron et al., 2000). In parallel, the decrease in MEP amplitudes that we observed could be related to changes in top-down influences on the spinal sensorimotor system (Eccles and Lundberg, 1959; Schomburg, 1990). Indeed, several cortical 
(Lundberg and Voorhoeve, 1962) and brainstem (Engberg et al., 1968a,b; Carstens and Campell, 1992)

structures can modulate the strength of synaptic transmission within spinal reflex circuits including those underlying the NWR.

Importantly, such sensori-motor interactions (i.e. the reduction of MEPs in flexor and extensor muscles of the stimulated hand) are probably not specific for nociception. Non-nociceptive electrical stimulation of both the median nerve and the digits provokes, 20-50 ms after stimulation, a suppression of MEPs recorded from proximal and distal upper limb muscles (Clouston et al., 1995; Manganotti et al., 1997; Bertolasi et al., 1998; Classen et al., 2000; Helmich et al., 2005;

Tamburin et al., 2005; Bikmullina et al., 2009a,b; Fischer and Orth, 2011). This afferent inhibition is thought mainly result from cortical inhibitory mechanisms in the sensorimotor cortex (Tokimura et al., 2000; Bikmullina et al., 2009a,b; Ferreri et al., 2012; Tsang et al., 2014; Kojima et al., 2015; Bailey et al., 2016; Noda et al., 2016) conveyed by cholinergic (Di Lazzaro et al., 2000, 2002) and GABAsergic pathways (Di Lazzaro et al., $2005,2007)$. This short-latency inhibition is followed by a later inhibitory period (200-1000 ms) which could result from mechanisms involving basal ganglia, thalamocortical (Sailer et al., 2003) and cortico-cortical interactions (Chen et al., 1999; Abbruzzese et al., 2001; Sailer et al., 2002). Whether the decrease in motor excitability we observed in the current study $150-400 \mathrm{~ms}$ after nociceptive stimulation can be explained by similar mechanisms remains an open question that cannot be answered with our experimental protocol.

Late-latency enhancement of motor excitability in the contralateral hand

Nociceptive stimuli delivered to the hand also induced a late-latency and long-lasting enhancement of the magnitude of the MEPs recorded from the non-laserstimulated hand, extending $600 \mathrm{~ms}$ onward after stimulus onset, at least for the FDI and ECR muscles. Again, one can only speculate on the nature of this late effect, which could result from interhemispheric interactions (Terada et al., 2012) and/or crossed interactions occurring at spinal level (Sherrington, 1910; Andersen et al., 2003; Emborg et al., 2009). It has also 
TB

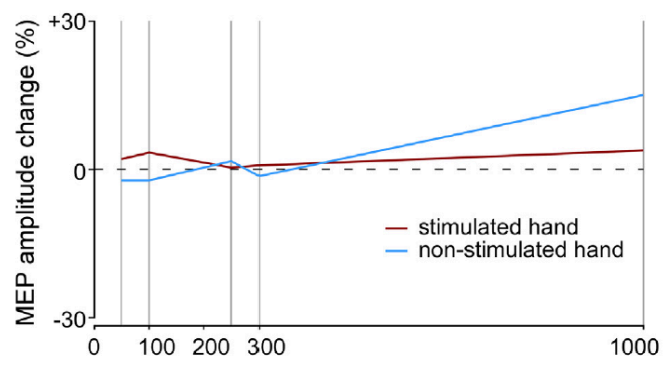

BB

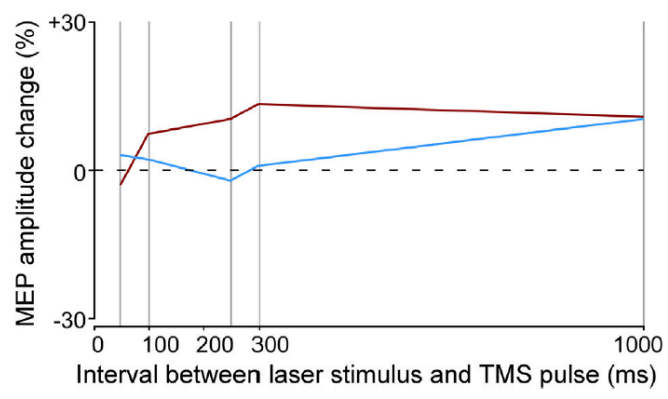

Fig. 6. Group-level average amplitude of the MEPs elicited in BB and TB muscles of the laser-stimulated and non-laser stimulated hands in the supplemental experiment. X-axis: time-interval between the onset of the laser stimulus and the onset of the TMS pulse. Y-axis: MEP amplitude, expressed as the percentage of change relative to the MEPs obtained at ISI=50 ms. No significant changes were observed.

to be noted that such an enhancement might not be limited to the non-stimulated limb as it was also observed in the FDI muscle of the stimulated hand. Furthermore, considering the late latency of this effect, it could reflect changes induced by nociceptive input conveyed by slow-conducting unmyelinated $\mathrm{C}$ fibers.

Using a similar experimental design, Chen et al.

(1999) characterized the temporal profile of the changes in motor excitability induced by non-nociceptive electrical stimulation of the median nerve at the level of the wrist. Such as in the present study, they observed an earlylatency enhancement of MEPs recorded from hand muscles of the stimulated hand, followed by a later attenuation of MEPs closely resembling the attenuation observed in the present study. The latency at which electrical stimulation of the median nerve exerted effects on motor excitability was shorter than the latency of the effects induced by laser stimulation. As discussed previously, this is easily explained by the time required for skin heating, heat transduction and nerve conduction of heat-evoked responses conveyed by thinly-myelinated Ad fibers as compared to the responses elicited by direct electrical activation of large-diameter Ab fibers.

However, contrasting with our results, non-nociceptive electrical stimulation did not appear to induce a late asymmetry of the MEPs elicited within hand muscles of the stimulated and non-stimulated limb (Chen et al., 1999), suggesting that the late asymmetric effect of the laser stimulus on motor excitability observed in the present study reflects sensori-motor interactions that are specific for nociception. This interpretation is consistent with the observations of Pereon and Guiheneuc (1995). In their experiment, MEPs were recorded from the right abductor digiti minimi muscle $200-700 \mathrm{~ms}$ after electrical stimulation of the left median nerve. Especially for highstimulation intensities, i.e. when the electrical stimulus 
was likely to activate small-diameter nociceptive afferents, they observed a late-latency enhancement of MEPs

similar to the enhancement observed in the present study. Spinal vs. cortical nociception-motor interactions In the present study, we did not test directly the excitability of spinal motoneurons. Therefore, we cannot determine with certainty whether the late effects of the nociceptive stimulus on motor excitability are due to interactions occurring at the level of the spinal cord, or interactions occurring at the level of the cortex. Valeriani et al. $(1999,2001)$ attempted to do so by comparing the effects of laser stimulation on the EMG responses elicited by TMS and anodal electrical stimulation of M1, assuming that anodal stimulation generates responses exclusively related to a direct activation of the cortico-spinal tract. However, several studies have suggested that this assumption might not always be true (Di Lazzaro et al., 1998). Other techniques to test spinal excitability suffer from other limitations. $\mathrm{H}$-waves recorded by electrical stimulation of a nerve trunk, in addition to being influenced by presynaptic, reciprocal and non-reciprocal inhibition (Knikou, 2008), are difficult to evoke at rest (Mazzocchio et al., 1995) and can be insensitive to changes, depending on the test reflex size (Crone et al., 1990). F-waves test only a fraction of the motoneurons pool (Espiritu et al., 2003). The recording of MEPs elicited by transcutaneous electrical stimulation of the cortico-spinal tract at cervico-medullary level could be an interesting mean (Taylor, 2006). However, cervico-medullary MEPs are difficult to obtain in relaxed subjects (Matsumoto et al., 2008). We attempted to record these responses in pilot experiments, but failed to obtain consistent responses compatible with the objective of assessing how they are modulated by a preceding laser stimulus. Further experiments relying on other techniques to disentangle changes in spinal and supraspinal motor excitability are thus needed.

Phasic vs. tonic pain

A number of studies investigated changes in motor excitability induced by tonic cutaneous pain (Romaniello et al., 2000; Farina et al., 2001; Fierro et al., 2010; Martel et al., 2017) or muscle pain (Romaniello et al., 2000; Le Pera et al., 2001; Svensson et al., 2003; Martin et al., 2008; Schabrun and Hodges, 2012; Schabrun et al., 2013; Burns et al., 2016). Changes in motor excitability induced by tonic pain and phasic pain could have different functions and reflect different mechanisms. For example, changes induced by phasic pain might be expected to prompt swift protective withdrawal responses, whereas changes induced by tonic pain may induce changes in motor behavior promoting healing and recovery (Farina et al., 2003).

Farina et al. (2001) showed that MEPs recorded from several muscles of the upper limb are reduced up to 20 30 min after the topical application of capsaicin on the skin overlying the FDI and FCR muscles. This inhibitory effect was interpreted as originating from a modulation at cortical level, because measures of peripheral and spinal excitability ( $\mathrm{F}-, \mathrm{H}$ - and $\mathrm{M}$-waves) remained unchanged throughout the experiment. Using paired-pulse measures of MEPs, Fierro et al. (2010) brought additional evidence of changes in cortical motor excitability induced by tonic cutaneous pain. A similar decrease in MEPs was observed after inducing tonic muscle pain (Le Pera et al., 2001; Svensson et al., 2003; Martin et al., 2008).

The suppression was explained by a reduction of excitability of both cortical and spinal motoneurons. Tonic 
muscle pain reduced not only the amplitude of MEPs elicited by M1 stimulation, but also the amplitude of the Hreflex (Le Pera et al., 2001), as well as the MEPs elicited by direct stimulation of descending motor tracts at the level of the foramen magnum (Svensson et al., 2003), indicating a reduction of spinal motoneuron excitability. Conversely, Martin et al. (2008) observed a facilitation of the MEPs elicited by direct stimulation of the corticospinal tract using cervico-medullary electrical stimulation without any concomitant increase of the MEPs elicited by cortical M1 stimulation, suggesting a facilitation of spinal motoneurons and a concomitant inhibition of cortical motoneurons. Inhibition at cortical level related to phasic and tonic pain might constitute a mean to induce "motor decerebration" allowing the spinal motor system to generate stronger protective reflex movements (Farina et al., 2003).

Study limitations

Lack of changes in forearm flexion and extensor muscles. In the supplemental experiment, we attempted to assess the effect of a laser stimulus on more proximal muscles controlling the flexion (BB) and extension (TB) of the forearm. In contrast with the clear modulation of the MEPs recorded from flexor and extensor muscles of the hand, we did not observe any significant effect of the nociceptive stimulus on the MEPs recorded from flexor and extensor muscles of the forearm. This lack of effect contrasts with the results of Valeriani et al. (2001), showing a significant decrease of MEPs in the BB muscle 170-220 ms after the onset of the laser stimulus. However, both results should be interpreted with caution, as the MEPs recorded from forearm muscles were of low amplitude (Fig. 5). This is related to the fact that activation of the motor representation of these muscles is more difficult than activation of the large motor representation of hand muscles (Wassermann et al., 1992; Metman et al., 1993). The non-linear stimulusresponse curve characterizing the relationship between TMS intensity and MEP amplitudes suggests that changes in these motor responses are dependent on the baseline amplitude of MEPs (Devanne et al. 1997). Therefore, further experiments investigating, for example, changes in the stimulus-response curve using a range of TMS stimulation intensities could be more appropriate to assess nociception-evoked changes in the motor excitability of proximal upper limb muscles. Large-amplitude MEP amplitudes recorded from the FDI muscles. Because the intensity of TMS was set such as to obtain reliable MEPs in FDI, FCR and ECR muscles, the MEPs obtained from the FDI muscle had a large average amplitude, suggesting that for this muscle, the stimulation was probably in the upper part of the sigmoidal input-output curve (Devanne et al., 1997). Importantly, this did not prevent us from observing a time-dependent change in amplitude of the MEPs recorded from the FDI muscle, including a significant increase at ISI $=100 \mathrm{~ms}$.

Effect of experimental context. Our experimental design required participants to rest both volar forearms against a table, and to refrain from moving the stimulated hand, in order to allow the recording of reliable MEPs. Future studies should examine whether limb position, location of the nociceptive stimulus, and the instruction to avoid stimulus-evoked movements (Bestmann and Duque, 2016; Duque et al., 2017) could 
have contributed to the results of the present study as well as the results of previous studies (Valeriani et al., 1999, 2001; Farina et al., 2001). Furthermore, at the end of each trial, participants were asked to verbally report the intensity of the percept elicited by the laser stimulus. Performing this task required to evaluate the stimulus, maintain information in working memory, and await a warning tone. Whether these could have influenced our results should thus be considered. An enhancement of MEPs recorded from the tongue has been described before the onset of speech. However, this was observed only shortly before speech onset (260 ms) (Neef et al., 2015) and, in the present study, the minimum time between the TMS pulse and the verbal report was $1-2 \mathrm{~s}$. Furthermore, an effect of speech on MEPs recorded from upper-limb muscles has, to the best of our knowledge, never been reported. Nevertheless, several studies have suggested that working memory tasks can induce changes in M1 excitability (Honey et al., 2000; Cairo et al., 2004). Most of these studies used protocols requiring the subject to press a button (Tomasino and Gremese, 2016). Because participants did not perform any manual task, it seems unlikely that such an effect of working memory would differentially affect the MEPs elicited in the hand receiving vs. not receiving the laser stimulus.

In conclusion, the present study shows that phasic pain delivered to one of the two hand dorsum induces an early excitatory effect on muscles of the stimulated hand, possibly related to the spinal nociceptive withdrawal reflex. Following this initial enhancement, the nociceptive stimulus induces an inhibitory effect in flexor and extensor muscles of both hands, but maximal at flexor muscles of the stimulated hand. This later effect may be related to nociceptive-motor interactions occurring at cortical level, although late interactions at spinal level cannot be ruled out. Finally, we show that nociceptive stimuli induce a very late and long-lasting facilitation in the flexor and extensor muscles of the non-stimulated hand. This long-lasting effect, which was not previously observed following non-nociceptive stimulation of the median nerve, could be specific for nociception.

\section{AUTHOR CONTRIBUTION}

M.A., J.D., G.D.I., A.M. conception and design of research; M.A., J.D. and A.M. performed the experiments; M.A. and A.M. analyzed the data; M.A., J. D., G.D.I., A.M. drafted the manuscript.

\section{ACKNOWLEDGMENT}

We gratefully acknowledge Lieven Desmet for his advice in statistical analysis.

\section{FUNDING}

A. M. and M. A. are supported by an ERC Starting Grant (PROBING PAIN). G.D.I. is supported by the Wellcome Trust (COLL JLARAXR), by an ERC Consolidator Grant (PAINSTRAT), and by the Medical Research Council UK. J. D. is supported by the "Fonds SpeÅL ciaux de Recherche" (FSR) of the UniversiteÅL catholique de Louvain, by the Belgian National Funds for Scientific Research (FRS-FNRS: MIS F.4512.14) and by the

"Fondation MeÅL dicale Reine Elisabeth" (FMRE).

\section{DECLARATIONS OF INTEREST}


None.

\section{REFERENCES}

Abbruzzese G, Marchese R, Buccolieri A, Gasparetto B, Trompetto C (2001) Abnormalities of sensorimotor integration in focal dystonia: a transcranial magnetic stimulation study. Brain 124:537-545. Andersen OK (2007) Studies of the organization of the human nociceptive withdrawal reflex. Focus on sensory convergence and stimulation site dependency. Acta Physiol (Oxf) 189(Suppl 654): $1-35$.

Andersen OK, Sonnenborg FA, Arendt-Nielsen L (1999) Modular organization of human leg withdrawal reflexes elicited by electrical stimulation of the foot sole. Muscle Nerve 22:1520-1530.

Andersen OK, Sonnenborg F, Matjacic Z, Arendt-Nielsen L (2003) Foot-sole reflex receptive fields for human withdrawal reflexes in symmetrical standing position. Exp Brain Res 152:434-443. Bailey AZ, Asmussen MJ, Nelson AJ (2016) Short-latency afferent inhibition determined by the sensory afferent volley. J

Neurophysiol 116:637-644.

Bank PJ, Peper CE, Marinus J, Beek PJ, van Hilten JJ (2013) Motor consequences of experimentally induced limb pain: a systematic review. Eur J Pain 17:145-157.

Bertolasi L, Priori A, Tinazzi M, Bertasi V, Rothwell JC (1998)

Inhibitory action of forearm flexor muscle afferents on corticospinal outputs to antagonist muscles in humans. J Physiol 511(Pt 3):947-956.

Bestmann S, Duque J (2015) Transcranial magnetic stimulation: decomposing the processes underlying action preparation.

Neuroscientist.

Bestmann S, Duque J (2016) Transcranial magnetic stimulation: decomposing the processes underlying action preparation. Neuroscientist 22:392-405.

Bikmullina R, Baumer T, Zittel S, Munchau A (2009a) Sensory afferent inhibition within and between limbs in humans. Clin Neurophysiol 120:610-618.

Bikmullina R, Kicic D, Carlson S, Nikulin VV (2009b)

Electrophysiological correlates of short-latency afferent inhibition: a combined EEG and TMS study. Exp Brain Res 194:517-526.

Bouhassira D, Le Bars D, Bolgert F, Laplane D, Willer JC (1993)

Diffuse noxious inhibitory controls in humans: a

neurophysiological investigation of a patient with a form of

Brown-Sequard syndrome. Ann Neurol 34:536-543.

Bromm B, Treede RD (1980) Withdrawal reflex, skin resistance

reaction and pain ratings due to electrical stimuli in man. Pain 9:339-354.

Bromm B, Treede RD (1984) Nerve fibre discharges, cerebral potentials and sensations induced by $\mathrm{CO} 2$ laser stimulation. Hum Neurobiol 3:33-40.

Bromm B, Treede RD (1987a) Human cerebral potentials evoked by CO2 laser stimuli causing pain. Exp Brain Res 67:153-162.

Bromm B, Treede RD (1987b) Pain related cerebral potentials: late and ultralate components. Int J Neurosci 33:15-23.

Burns E, Chipchase LS, Schabrun SM (2016) Reduced short- and

long-latency afferent inhibition following acute muscle pain: a potential role in the recovery of motor output. Pain Med. Caccia MR, McComas AJ, Upton AR, Blogg T (1973) Cutaneous reflexes in small muscles of the hand. J Neurol Neurosurg Psychiatry 36:960-977.

Cairo TA, Liddle PF, Woodward TS, Ngan ET (2004) The influence of working memory load on phase specific patterns of cortical activity. Brain Res Cogn Brain Res 21:377-387. Cambier J, Dehen H, Bathien N (1974) Upper limb cutaneous polysynaptic reflexes. J Neurol Sci 22:39-49.

Campbell IG, Carstens E, Watkins LR (1991) Comparison of human pain sensation and flexion withdrawal evoked by noxious radiant heat. Pain 45:259-268.

Carstens E, Campell IG (1992) Responses of motor units during the hind limb flexion withdrawal reflex evoked by noxious skin heating: phasic and prolonged suppression by midbrain stimulation and comparison with simultaneously recorded dorsal horn units. Pain 48:215-226.

Chen R, Corwell B, Hallett M (1999) Modulation of motor cortex excitability by median nerve and digit stimulation. Exp Brain Res 129:77-86.

Cincotta M, Borgheresi A, Jung P, Balestrieri F, Giovannelli F, Zaccara G, Ziemann U (2005) Physical interactions between induced electrical fields can have substantial effects on neuronal excitation during simultaneous TMS of two brain areas. Clin 
Neurophysiol 116:1733-1742.

Classen J, Steinfelder B, Liepert J, Stefan K, Celnik P, Cohen LG, Hess A, Kunesch E, et al. (2000) Cutaneomotor integration in humans is somatotopically organized at various levels of the nervous system and is task dependent. Exp Brain Res 130:48-59. Claus D, Harding AE, Hess CW, Mills KR, Murray NM, Thomas PK (1988) Central motor conduction in degenerative ataxic disorders: a magnetic stimulation study. J Neurol Neurosurg Psychiatry 51:790-795.

Clouston PD, Kiers L, Menkes D, Sander H, Chiappa K, Cros D (1995) Modulation of motor activity by cutaneous input: inhibition of the magnetic motor evoked potential by digital electrical stimulation. Electroencephalogr Clin Neurophysiol 97:114-125.

Cooke DF, Graziano MS (2003) Defensive movements evoked by air puff in monkeys. J Neurophysiol 90:3317-3329.

Cooke DF, Graziano MS (2004) Sensorimotor integration in the precentral gyrus: polysensory neurons and defensive

movements. J Neurophysiol 91:1648-1660.

Crone C, Hultborn H, Mazieres L, Morin C, Nielsen J, Pierrot-

Deseilligny E (1990) Sensitivity of monosynaptic test reflexes to facilitation and inhibition as a function of the test reflex size: a study in man and the cat. Exp Brain Res 81:35-45.

Curtis DR, Eccles JC (1959) The time courses of excitatory and inhibitory synaptic actions. J Physiol 145:529-546.

Derosiere G, Billot M, Ward ET, Perrey S (2015) Adaptations of motor neural structures' activity to lapses in attention. Cereb Cortex 25:66-74.

Devanne H, Lavoie BA, Capaday C (1997) Input-output properties and gain changes in the human corticospinal pathway. Exp Brain Res 114:329-338.

Di Lazzaro V, Oliviero A, Profice P, Saturno E, Pilato F, Insola A, Mazzone P, Tonali P, et al. (1998) Comparison of descending volleys evoked by transcranial magnetic and electric stimulation in conscious humans. Electroencephalogr Clin Neurophysiol 109:397-401.

Di Lazzaro V, Oliviero A, Profice P, Pennisi MA, Di Giovanni S, Zito G, Tonali P, Rothwell JC (2000) Muscarinic receptor blockade has differential effects on the excitability of intracortical circuits in the human motor cortex. Exp Brain Res 135:455-461.

Di Lazzaro V, Oliviero A, Tonali PA, Marra C, Daniele A, Profice P, Saturno E, Pilato F, et al. (2002) Noninvasive in vivo assessment of cholinergic cortical circuits in $\mathrm{AD}$ using transcranial magnetic stimulation. Neurology 59:392-397.

Di Lazzaro V, Oliviero A, Pilato F, Saturno E, Dileone M, Mazzone P, Insola A, Tonali PA, et al. (2004) The physiological basis of transcranial motor cortex stimulation in conscious humans. Clin Neurophysiol 115:255-266.

Di Lazzaro V, Oliviero A, Saturno E, Dileone M, Pilato F, Nardone R, Ranieri F, Musumeci G, et al. (2005) Effects of lorazepam on short latency afferent inhibition and short latency intracortical inhibition in humans. J Physiol 564:661-668.

Di Lazzaro V, Pilato F, Dileone M, Profice P, Ranieri F, Ricci V, Bria P, Tonali PA, et al. (2007) Segregating two inhibitory circuits in human motor cortex at the level of GABAA receptor subtypes: a TMS study. Clin Neurophysiol 118:2207-2214.

Donaldson TS (1968) Robustness of the F-test to errors of both kinds and the correlation between the numerator and denominator of the F-ratio. J Am Stat Assoc 63:660-676.

Dube JA, Mercier C (2011) Effect of pain and pain expectation on primary motor cortex excitability. Clin Neurophysiol $122: 2318-2323$

Dum RP, Levinthal DJ, Strick PL (2009) The spinothalamic system targets motor and sensory areas in the cerebral cortex of monkeys. J Neurosci 29:14223-14235.

252 M. Algoet et al. / Neuroscience 386 (2018) 240-255

Duque J, Greenhouse I, Labruna L, Ivry RB (2017) Physiological markers of motor inhibition during human behavior. Trends Neurosci 40:219-236.

Eccles RM, Lundberg A (1959) Supraspinal control of interneurones mediating spinal reflexes. J Physiol 147:565-584.

Eckert N, Riley ZA (2013) The nociceptive withdrawal reflex does not adapt to joint position change and short-term motor practice. F1000Res 2:158.

Emborg J, Spaich EG, Andersen OK (2009) Withdrawal reflexes examined during human gait by ground reaction forces: site and gait phase dependency. Med Biol Eng Comput 47:29-39.

Engberg I, Lundberg A, Ryall RW (1968a) Is the tonic decerebrate inhibition of reflex paths mediated by monoaminergic pathways? Acta Physiol Scand 72:123-133.

Engberg I, Lundberg A, Ryall RW (1968b) Reticulospinal inhibition of 
transmission in reflex pathways. J Physiol 194:201-223.

Espiritu MG, Lin CS, Burke D (2003) Motoneuron excitability and the F wave. Muscle Nerve 27:720-727.

Farina S, Valeriani M, Rosso T, Aglioti S, Tamburin S, Fiaschi A, Tinazzi M (2001) Transient inhibition of the human motor cortex by capsaicin-induced pain. A study with transcranial magnetic stimulation. Neurosci Lett 314:97-101.

Farina S, Tinazzi M, Le Pera D, Valeriani M (2003) Pain-related modulation of the human motor cortex. Neurol Res 25:130-142.

Feise RJ (2002) Do multiple outcome measures require p-value

adjustment? BMC Med Res Methodol 2:8.

Ferbert A, Priori A, Rothwell JC, Day BL, Colebatch JG, Marsden CD

(1992) Interhemispheric inhibition of the human motor cortex. J

Physiol 453:525-546.

Ferreri F, Ponzo D, Hukkanen T, Mervaala E, Kononen M,

Pasqualetti P, Vecchio F, Rossini PM, et al. (2012) Human

brain cortical correlates of short-latency afferent inhibition: a

combined EEG-TMS study. J Neurophysiol 108:314-323.

Fierro B, De Tommaso M, Giglia F, Giglia G, Palermo A, Brighina F

(2010) Repetitive transcranial magnetic stimulation (rTMS) of the

dorsolateral prefrontal cortex (DLPFC) during capsaicin-induced pain: modulatory effects on motor cortex excitability. Exp Brain Res 203:31-38.

Fischer M, Orth M (2011) Short-latency sensory afferent inhibition: conditioning stimulus intensity, recording site, and effects of $1 \mathrm{~Hz}$ repetitive TMS. Brain Stimul 4:202-209.

Floeter MK (2003) Cutaneous silent periods. Muscle Nerve 28:391-401.

Floeter MK, Gerloff C, Kouri J, Hallett M (1998) Cutaneous withdrawal reflexes of the upper extremity. Muscle Nerve 21:591-598.

Frot M, Magnin M, Mauguiere F, Garcia-Larrea L (2013) Cortical representation of pain in primary sensory-motor areas (S1/M1)-a study using intracortical recordings in humans. Hum Brain Mapp 34:2655-2668.

Glass GV, Peckham PD, Sanders JR (1972) Consequences of failure

to meet assumptions underlying the fixed effects analysis of

variance and covariance. Rev Educ Res 42:237-288.

Grandjean J, Derosiere G, Vassiliadis P, Quemener L, Wilde Y,

Duque J (2018) Towards assessing corticospinal excitability

bilaterally: validation of a double-coil TMS method. J Neurosci

Methods 293:162-168.

Grimby L (1963) Normal plantar response: integration of flexor and

extensor reflex components. J Neurol Neurosurg Psychiatry

26:39-50.

Hallett M (2000) Transcranial magnetic stimulation and the human

brain. Nature 406:147-150.

Hanajima R, Ugawa Y, Machii K, Mochizuki H, Terao Y, Enomoto H, Furubayashi T, Shiio Y, et al. (2001) Interhemispheric facilitation

of the hand motor area in humans. J Physiol 531:849-859.

Harwell MR, Rubinstein EN, Hayes WS, Olds CC (1992)

Summarizing Monte Carlo results in methodological research:

the one- and two-factor fixed effects ANOVA cases. J Educ Stat 17:315-339.

Helmich RC, Baumer T, Siebner HR, Bloem BR, Munchau A (2005)

Hemispheric asymmetry and somatotopy of afferent inhibition in

healthy humans. Exp Brain Res 167:211-219.

Hodges PW, Tucker K (2011) Moving differently in pain: a new theory

to explain the adaptation to pain. Pain 152:S90-98.

Homberg V, Stephan KM, Netz J (1991) Transcranial stimulation of

motor cortex in upper motor neurone syndrome: its relation to the

motor deficit. Electroencephalogr Clin Neurophysiol 81:377-388.

Honey GD, Bullmore ET, Sharma T (2000) Prolonged reaction time to

a verbal working memory task predicts increased power of

posterior parietal cortical activation. NeuroImage 12:495-503.

Iannetti GD, Mouraux A (2010) From the neuromatrix to the pain

matrix (and back). Exp Brain Res 205:1-12.

Inghilleri M, Berardelli A, Cruccu G, Manfredi M, Priori A, Rothwell JC

(1995) Inhibition of hand muscle motoneurones by peripheral

nerve stimulation in the relaxed human subject. Antidromic versus

orthodromic input. Electroencephalogr Clin Neurophysiol

97:63-68

Inghilleri M, Cruccu G, Argenta M, Polidori L, Manfredi M (1997)

Silent period in upper limb muscles after noxious cutaneous

stimulation in man. Electroencephalogr Clin Neurophysiol

105:109-115.

Kahya MC, Yavuz SU, Turker KS (2010) Cutaneous silent period in

human FDI motor units. Exp Brain Res 205:455-463.

Kakigi R, Endo C, Neshige R, Kuroda Y, Shibasaki H (1991)

Estimation of conduction velocity of A delta fibers in humans

Muscle Nerve 14:1193-1196. 
Knikou M (2008) The H-reflex as a probe: pathways and pitfalls. J Neurosci Methods 171:1-12.

Kofler M (2003) Functional organization of exteroceptive inhibition

following nociceptive electrical fingertip stimulation in humans.

Clin Neurophysiol 114:973-980.

Kofler M, Glocker FX, Leis AA, Seifert C, Wissel J, Kronenberg MF, Fuhr P (1998) Modulation of upper extremity motoneurone excitability following noxious finger tip stimulation in man: a study with transcranial magnetic stimulation. Neurosci Lett 246:97-100.

Kofler M, Fuhr P, Leis AA, Glocker FX, Kronenberg MF, Wissel J, Stetkarova I (2001) Modulation of upper extremity motor evoked potentials by cutaneous afferents in humans. Clin Neurophysiol 112:1053-1063.

Kofler M, Valls-Sole J, Fuhr P, Schindler C, Zaccaria BR, Saltuari L (2008) Sensory modulation of voluntary and TMS-induced

activation in hand muscles. Exp Brain Res 188:399-409.

Kojima S, Onishi H, Miyaguchi S, Kotan S, Sugawara K, Kirimoto H, Tamaki H (2015) Effects of cathodal transcranial direct current stimulation to primary somatosensory cortex on short-latency afferent inhibition. NeuroReport 26:634-637.

Kranz H, Adorjani C, Baumgartner G (1973) The effect of nociceptive cutaneous stimuli on human motoneurons. Brain 96:571-590.

Landgren S, Phillips CG, Porter R (1962) Minimal synaptic actions of pyramidal impulses on some alpha motoneurones of the baboon's hand and forearm. J Physiol 161:91-111.

Le Pera D, Graven-Nielsen T, Valeriani M, Oliviero A, Di Lazzaro V, Tonali PA, Arendt-Nielsen L (2001) Inhibition of motor system excitability at cortical and spinal level by tonic muscle pain. Clin Neurophysiol 112:1633-1641.

Lenoir C, Huang G, Vandermeeren Y, Hatem SM, Mouraux A (2017) Human primary somatosensory cortex is differentially involved in vibrotaction and nociception. J Neurophysiol 118:317-330. Lix LM, Keselman JC, Keselman HJ (1996) Consequences of assumption violations revisited: a quantitative review of alternatives to the one-way analysis of variance $\mathrm{F}$ test. Rev Educ Res 66:579-619.

Lundberg A, Voorhoeve P (1962) Effects from the pyramidal tract on spinal reflex arcs. Acta Physiol Scand 56:201-219.

Manganotti P, Zanette G, Bonato C, Tinazzi M, Polo A, Fiaschi A (1997) Crossed and direct effects of digital nerves stimulation on motor evoked potential; a study with magnetic brain stimulation. Electroencephalogr Clin Neurophysiol 105:280-289.

Martel M, Harvey MP, Houde F, Balg F, Goffaux P, Leonard G (2017) Unravelling the effect of experimental pain on the corticomotor system using transcranial magnetic stimulation and electroencephalography. Exp Brain Res 235:1223-1231.

M. Algoet et al. / Neuroscience 386 (2018) 240-255 253

Martin PG, Weerakkody N, Gandevia SC, Taylor JL (2008) Group III and IV muscle afferents differentially affect the motor cortex and motoneurones in humans. J Physiol 586:1277-1289.

Matsumoto H, Hanajima R, Hamada M, Terao Y, Yugeta A, InomataTerada S, Nakatani-Enomoto S, Tsuji S, et al. (2008) Doublepulse magnetic brain stem stimulation: mimicking successive descending volleys. J Neurophysiol 100:3437-3444.

Mazzocchio R, Rothwell JC, Rossi A (1995) Distribution of Ia effects onto human hand muscle motoneurones as revealed using an $\mathrm{H}$ reflex technique. J Physiol 489(Pt 1):263-273.

McLellan DL (1973) The electromyographic silent period produced by supramaximal electrical stimulation in normal man. J Neurol Neurosurg Psychiatry 36:334-341.

Merton PA (1951) The silent period in a muscle of the human hand. J Physiol 114:183-198.

Metman LV, Bellevich JS, Jones SM, Barber MD, Streletz LJ (1993) Topographic mapping of human motor cortex with transcranial magnetic stimulation: homunculus revisited. Brain Topogr 6:13-19. Moayedi M, Liang M, Sim AL, Hu L, Haggard P, Iannetti GD (2015)

Laser-evoked vertex potentials predict defensive motor actions.

Cereb Cortex 25:4789-4798.

Mouraux A, Guerit JM, Plaghki L (2003) Non-phase locked electroencephalogram (EEG) responses to $\mathrm{CO} 2$ laser skin stimulations may reflect central interactions between A partial partial differential- and C-fibre afferent volleys. Clin Neurophysiol 114:710-722.

Neef NE, Hoang TN, Neef A, Paulus W, Sommer M (2015) Speech dynamics are coded in the left motor cortex in fluent speakers but not in adults who stutter. Brain 138:712-725.

Noda Y, Cash RF, Zomorrodi R, Dominguez LG, Farzan F, Rajji TK, Barr MS, Chen R, et al. (2016) A combined TMS-EEG study of short-latency afferent inhibition in the motor and dorsolateral 
prefrontal cortex. J Neurophysiol 116:938-948.

Pellicciari MC, Miniussi C, Ferrari C, Koch G, Bortoletto M (2016) Ongoing cumulative effects of single TMS pulses on corticospinal

excitability: an intra- and inter-block investigation. Clin

Neurophysiol 127:621-628.

Pereon Y, Guiheneuc P (1995) Late facilitations of motor evoked

potentials by contralateral mixed nerve stimulation.

Electroencephalogr Clin Neurophysiol 97:126-130.

Peterson CL, Riley ZA, Krepkovich ET, Murray WM, Perreault EJ

(2014) Withdrawal reflexes in the upper limb adapt to arm posture

and stimulus location. Muscle Nerve 49:716-723.

Peyron R, Laurent B, Garcia-Larrea L (2000) Functional imaging of

brain responses to pain. A review and meta-analysis (2000).

Neurophysiol Clin 30:263-288.

Plaghki L, Delisle D, Godfraind JM (1994) Heterotopic nociceptive

conditioning stimuli and mental task modulate differently the

perception and physiological correlates of short CO2 laser stimuli.

Pain 57:181-192.

Ploner M, Gross J, Timmermann L, Pollok B, Schnitzler A (2006) Pain

suppresses spontaneous brain rhythms. Cereb Cortex

16:537-540.

Raij TT, Vartiainen NV, Jousmaki V, Hari R (2003) Effects of

interstimulus interval on cortical responses to painful laser

stimulation. J Clin Neurophysiol 20:73-79.

Raij TT, Forss N, Stancak A, Hari R (2004) Modulation of motorcortex

oscillatory activity by painful Adelta- and C-fiber stimuli.

NeuroImage 23:569-573.

Rall W, Burke RE, Smith TG, Nelson PG, Frank K (1967) Dendritic

location of synapses and possible mechanisms for the

monosynaptic EPSP in motoneurons. J Neurophysiol

30:1169-1193.

Romaniello A, Cruccu G, McMillan AS, Arendt-Nielsen L, Svensson P

(2000) Effect of experimental pain from trigeminal muscle and

skin on motor cortex excitability in humans. Brain Res

882:120-127.

Romaniello A, Truini A, Galeotti F, De Lena C, Willer JC, Cruccu G

(2004) Cutaneous silent period in hand muscle is evoked by laser stimulation of the palm, but not the hand dorsum. Muscle Nerve 29:870-872.

Rossini PM, Caramia MD, Zarola F (1987) Mechanisms of nervous propagation along central motor pathways: noninvasive evaluation in healthy subjects and in patients with neurological disease. Neurosurgery 20:183-191.

Rothman KJ (1990) No adjustments are needed for multiple comparisons. Epidemiology 1:43-46.

Sailer A, Molnar GF, Cunic DI, Chen R (2002) Effects of peripheral sensory input on cortical inhibition in humans. J Physiol 544:617-629.

Sailer A, Molnar GF, Paradiso G, Gunraj CA, Lang AE, Chen R (2003) Short and long latency afferent inhibition in Parkinson's disease. Brain 126:1883-1894.

Sandrini G, Serrao M, Rossi P, Romaniello A, Cruccu G, Willer JC (2005) The lower limb flexion reflex in humans. Prog Neurobiol 77:353-395.

Schabrun SM, Hodges PW (2012) Muscle pain differentially modulates short interval intracortical inhibition and intracortical facilitation in primary motor cortex. J Pain 13:187-194. Schabrun SM, Jones E, Kloster J, Hodges PW (2013) Temporal association between changes in primary sensory cortex and corticomotor output during muscle pain. Neuroscience 235:159-164.

Schomburg ED (1990) Spinal sensorimotor systems and their supraspinal control. Neurosci Res 7:265-340.

Schouenborg J, Kalliomaki J (1990) Functional organization of the nociceptive withdrawal reflexes. I. Activation of hindlimb muscles in the rat. Exp Brain Res 83:67-78.

Serrao M, Pierelli F, Don R, Ranavolo A, Cacchio A, Curra A,

Sandrini G, Frascarelli M, et al. (2006) Kinematic and

electromyographic study of the nociceptive withdrawal reflex in the upper limbs during rest and movement. J Neurosci 26:3505-3513.

Serrao M, Ranavolo A, Andersen OK, Don R, Draicchio F, Conte C, Di Fabio R, Perrotta A, et al. (2012) Reorganization of multimuscle and joint withdrawal reflex during arm movements in post-stroke hemiparetic patients. Clin Neurophysiol 123:527-540

Sherrington CS (1910) Flexion-reflex of the limb, crossed extensionreflex, and reflex stepping and standing. J Physiol 40:28-121.

Spiegel J, Hansen C, Treede RD (1996) Laser-evoked potentials after painful hand and foot stimulation in humans: evidence for 
generation of the middle-latency component in the secondary somatosensory cortex. Neurosci Lett 216:179-182.

Suppa A, Biasiotta A, Belvisi D, Marsili L, La Cesa S, Truini A, Cruccu

G, Berardelli A (2013) Heat-evoked experimental pain induces

long-term potentiation-like plasticity in human primary motor cortex. Cereb Cortex 23:1942-1951.

Svensson P, Miles TS, McKay D, Ridding MC (2003) Suppression of

motor evoked potentials in a hand muscle following prolonged painful stimulation. Eur J Pain 7:55-62.

Tamburin S, Manganotti P, Zanette G, Fiaschi A (2001)

Cutaneomotor integration in human hand motor areas:

somatotopic effect and interaction of afferents. Exp Brain Res

$141: 232-241$.

Tamburin S, Fiaschi A, Andreoli A, Marani S, Zanette G (2005)

Sensorimotor integration to cutaneous afferents in humans: the effect of the size of the receptive field. Exp Brain Res

167:362-369.

Tarkka IM, Treede RD, Bromm B (1992) Sensory and movementrelated cortical potentials in nociceptive and auditory reaction time

tasks. Acta Neurol Scand 86:359-364.

Taylor JL (2006) Stimulation at the cervicomedullary junction in human subjects. J Electromyogr Kinesiol 16:215-223.

Terada K, Umeoka S, Usui N, Baba K, Usui K, Fujitani S, Matsuda K, Tottori T, et al. (2012) Uneven interhemispheric connections between left and right primary sensori-motor areas. Hum Brain Mapp 33:14-26.

Tokimura H, Di Lazzaro V, Tokimura Y, Oliviero A, Profice P, Insola A, Mazzone P, Tonali P, et al. (2000) Short latency inhibition of human hand motor cortex by somatosensory input from the hand.

J Physiol 523(Pt 2):503-513.

254 M. Algoet et al. / Neuroscience 386 (2018) 240-255

Tomasino B, Gremese M (2016) The Cognitive Side of M1. Front

Hum Neurosci 10:298.

Tran TD, Lam K, Hoshiyama M, Kakigi R (2001) A new method fo measuring the conduction velocities of Abeta-, Adelta- and Cfibers following electric and $\mathrm{CO}(2)$ laser stimulation in humans.

Neurosci Lett 301:187-190.

Triggs WJ, Calvanio R, Macdonell RA, Cros D, Chiappa KH (1994)

Physiological motor asymmetry in human handedness: evidence

from transcranial magnetic stimulation. Brain Res 636:270-276.

Tsang P, Jacobs MF, Lee KG, Asmussen MJ, Zapallow CM, Nelson

AJ (2014) Continuous theta-burst stimulation over primary

somatosensory cortex modulates short-latency afferent

inhibition. Clin Neurophysiol 125:2253-2259.

Turken AU, Swick D (1999) Response selection in the human anterior cingulate cortex. Nat Neurosci 2:920-924.

Uncini A, Kujirai T, Gluck B, Pullman S (1991) Silent period induced by cutaneous stimulation. Electroencephalogr Clin Neurophysiol

81:344-352.

Urban PP, Solinski M, Best C, Rolke R, Hopf HC, Dieterich M (2004)

Different short-term modulation of cortical motor output to distal

and proximal upper-limb muscles during painful sensory nerve

stimulation. Muscle Nerve 29:663-669.

Valentini E, Hu L, Chakrabarti B, Hu Y, Aglioti SM, Iannetti GD

(2012a) The primary somatosensory cortex largely contributes to

the early part of the cortical response elicited by nociceptive stimuli. NeuroImage 59:1571-1581.

Valentini E, Liang M, Aglioti SM, Iannetti GD (2012b) Seeing touch

and pain in a stranger modulates the cortical responses elicited by

somatosensory but not auditory stimulation. Hum Brain Mapp

$33: 2873-2884$

Valeriani M, Restuccia D, Di Lazzaro V, Oliviero A, Profice P, Le Pera

D, Saturno E, Tonali P (1999) Inhibition of the human primary

motor area by painful heat stimulation of the skin. Clin

Neurophysiol 110:1475-1480.

Valeriani M, Restuccia D, Di Lazzaro V, Oliviero A, Le Pera D, Profice

P, Saturno E, Tonali P (2001) Inhibition of biceps brachii muscle

motor area by painful heat stimulation of the skin. Exp Brain Res 139:168-172.

Vassiliadis P, Grandjean J, Derosiere G, de Wilde Y, Quemener L, Duque J (2018) Using a double-coil TMS protocol to assess preparatory inhibition bilaterally. Front Neurosci 12:139. Wassermann EM, McShane LM, Hallett M, Cohen LG (1992)

Noninvasive mapping of muscle representations in human moto cortex. Electroencephalogr Clin Neurophysiol 85:1-8.

Xu X, Kanda M, Shindo K, Fujiwara N, Nagamine T, Ikeda A, Honda

M, Tachibana N, et al. (1995) Pain-related somatosensory evoked

potentials following $\mathrm{CO} 2$ laser stimulation of foot in man.

Electroencephalogr Clin Neurophysiol 96:12-23. 